\title{
THE EFFECTS OF BLAST LAG IN ABRASIVE JET MACHINED MICRO- CHANNEL INTERSECTIONS
}

by

\section{Soheil Shafagh}

Bachelor of Mechanical Engineering, Ryerson University, Toronto, Canada 2017

\author{
A thesis \\ Presented to Ryerson University \\ In partial fulfillment of the \\ Requirement for the degree of \\ Master of Applied Science \\ In the Program of \\ Mechanical and Industrial Engineering
}

Toronto, Ontario, Canada, 2019

(C) Soheil Shafagh 2019 


\section{AUTHOR'S DECLARATION FOR ELECTRONIC SUBMISSION OF THESIS}

I hereby declare that I am the sole author of this thesis. This is a true copy of the thesis, including any required final revisions, as accepted by my examiners.

I authorize Ryerson University to lend this thesis to other institutions or individuals for the purpose of scholarly research.

I further authorize Ryerson University to reproduce this thesis by photocopying or by other means, in total or in part, at the request of other institutions or individuals for the purpose of scholarly research.

I understand that my thesis may be made electronically available to the public. 


\title{
Abstract
}

\section{The effects of blast lag in abrasive jet machined micro-channel intersections}

\author{
Soheil Shafagh \\ Master of Applied Science, 2019 \\ Mechanical and Industrial Engineering \\ Ryerson University
}

\begin{abstract}
Abrasive jet micro-machining (AJM) uses compressed air carrying abrasive solid particles to micro-machine a variety of features into surfaces. If the features are smaller than a few $\mathrm{mm}$, then a patterned erosion-resistant mask is used to protect the substrate material, leaving exposed areas to define the features. Previous investigations have revealed a 'blast lag' phenomenon in which, for the same dose of abrasive particles, the etched depth of micro-channels and holes tends to decrease as the features become narrower. Blast lag occurs when using AJM on brittle substrates because of the natural tendency to rapidly form a V-shaped cross-sectional profile which inhibits abrasive particle strikes on the narrow vertex at the feature centerline. In this thesis, for the first time, the blast lag phenomenon is studied when using AJM to machine a network of microfluidic channels. It is found that, in some cases, differences in blast lag occurring at channel intersections and within the channels themselves, can lead to channel networks of non-uniform depth. A previously developed surface evolution model is used to predict the onset of blast lag in the channels and intersections, and thus explain these differences. Finally, methods to eliminate the differences are discussed.
\end{abstract}




\section{Acknowledgements}

I would like to thank:

Dr. Marcello Papini for providing me with the opportunity to join his research team and his persistent and friendly support, encouragement, patience and advice during my MASc.

* The financial support of the Natural Sciences and Engineering Research Council of Canada (NSERC).

Ryerson University for the fantastic facilities and equipment provided for this research.

Alan Machin, Qiang Li, Chao Ma, Grace He, Joseph Amankrah, Andrew Heim, and Roy Churaman for their technical support.

* My good friends Dr. Ali Nouhi, Farbod Ahmadzadeh, Navid Arani, Ehsan Azarsa, Aria Ghazavi, Seyed Navid Mousavi, Iman Moghimi, Ali Shafagh Nya and Reza Danesh for their valuable consultations. 


\section{Dedication}

This thesis is dedicated to my beloved parents, and all my loved ones. 


\section{Table of Contents}

AUTHOR'S DECLARATION FOR ELECTRONIC SUBMISSION OF THESIS ..................... ii

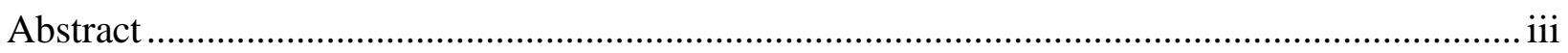

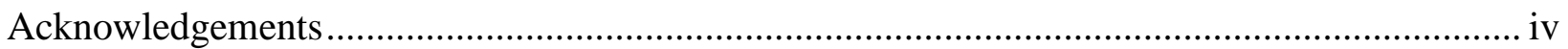

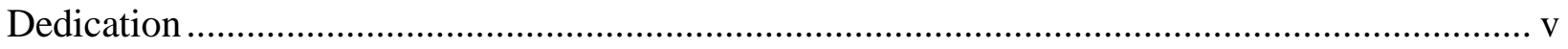

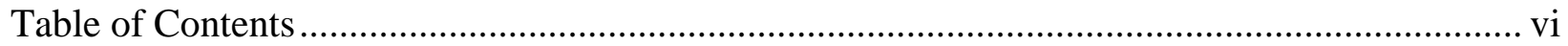

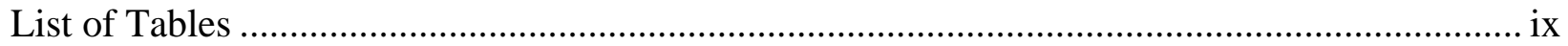

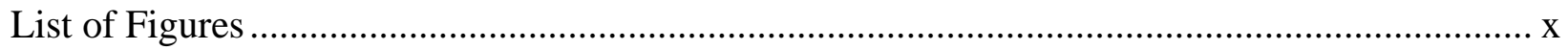

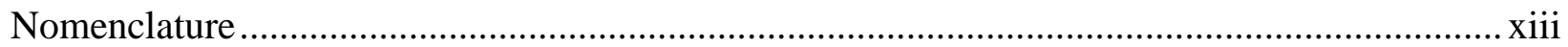

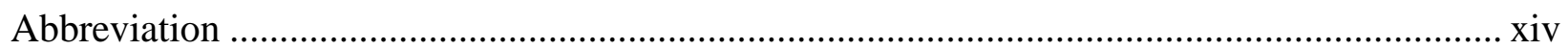

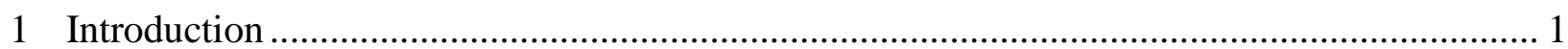

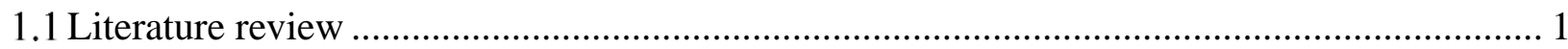

1.1.1 Constructive solid particle erosion ................................................................. 1

1.1.2 The abrasive jet micro-machining method ......................................................... 1

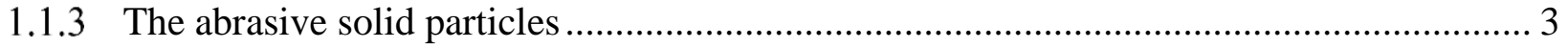

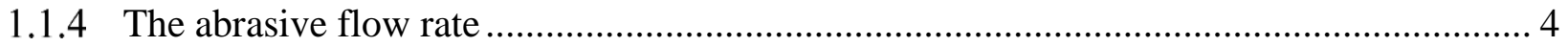

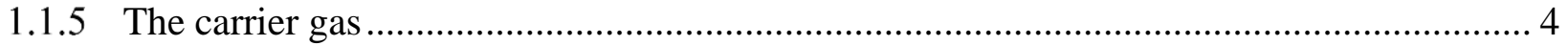

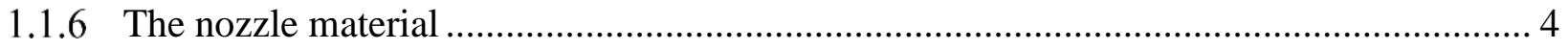

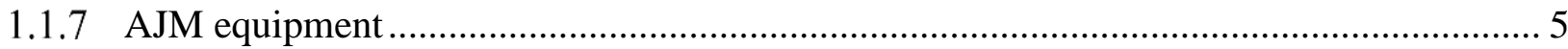

1.1.8 Comparison with traditional micro-machining methods........................................... 6 


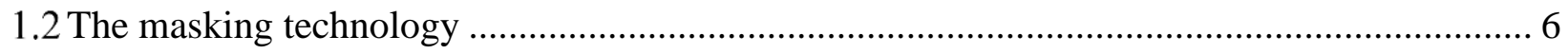

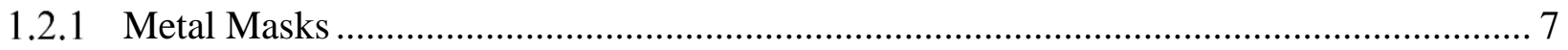

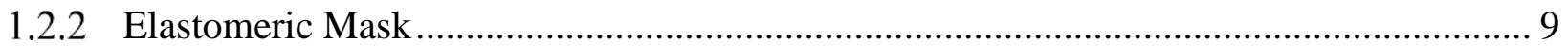

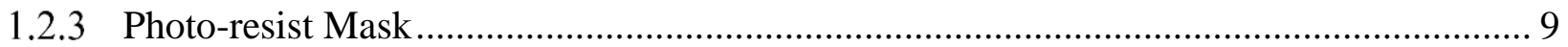

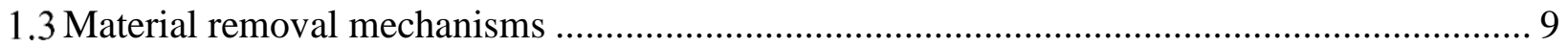

1.3.1 The micro-machining mechanism ..................................................................... 9

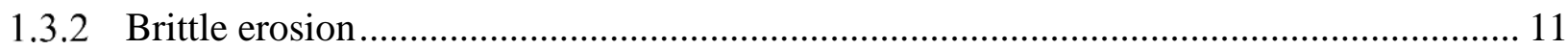

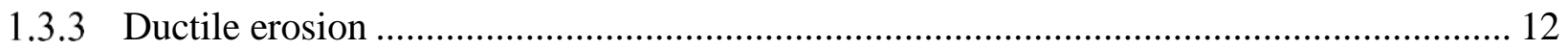

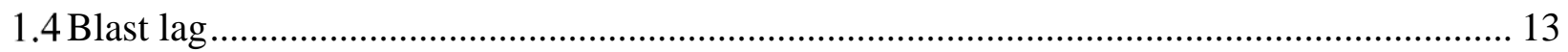

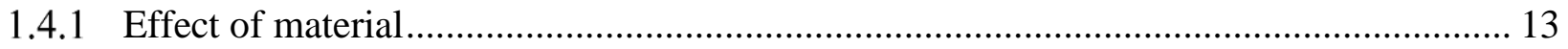

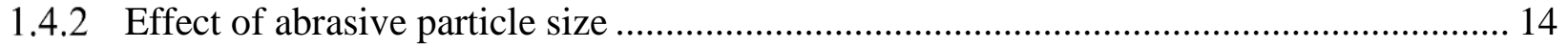

1.4.2.1 Effect on the access of narrow areas along the center of the channel ........................ 14

1.4.2.2 Effect on the erosion near the mask edge and relation to sidewall steepness ............... 14

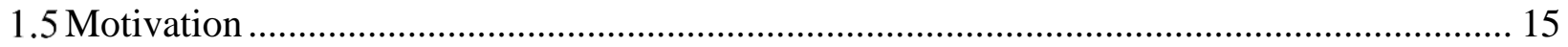

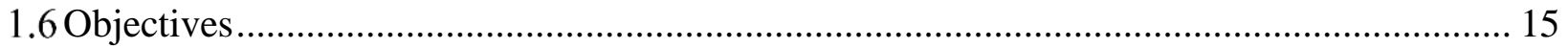

2 Measurement and modeling of blast lag in a micro-channel network ............................... 16

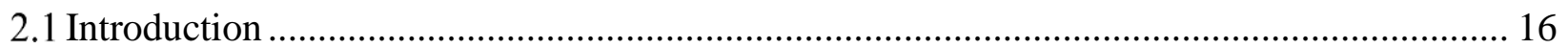

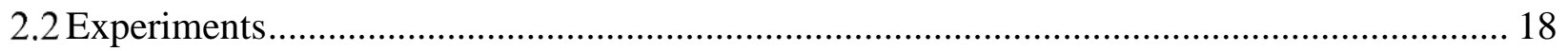

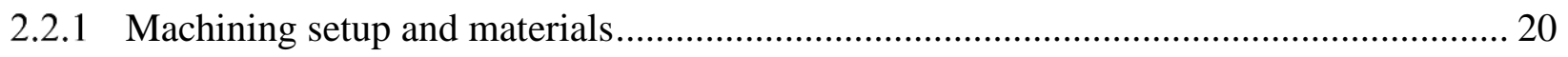

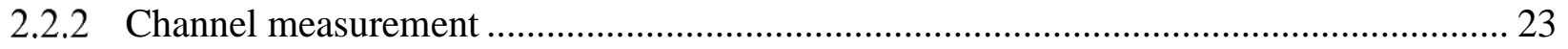


2.3 Results and Discussion

2.3.1 Absolute depth ratio of masked channels $\left(k_{s}\right)$...................................................... 25

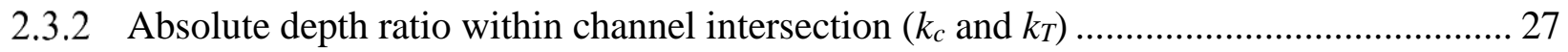

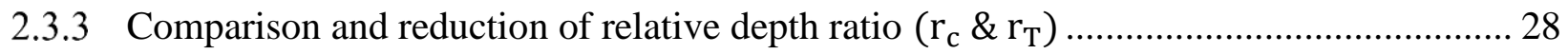

2.3.4 Reduction of differences in blast lag in microfluidic networks ................................. 32

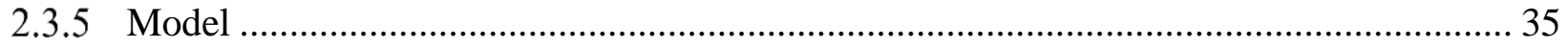

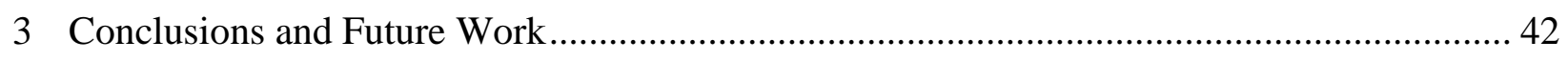

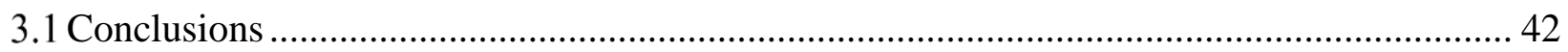

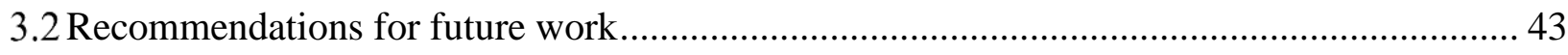

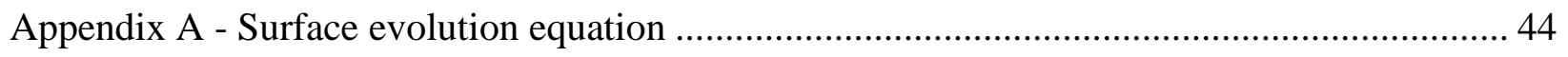

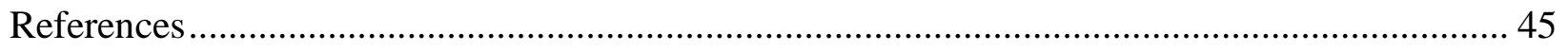




\section{List of Tables}

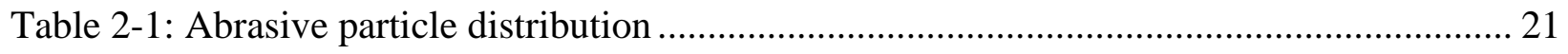

Table 2-2: Process parameters used for AJM experiments................................................ 21

Table 2-3: Predictions of surface evolution model ................................................................ 38 


\section{List of Figures}

Figure 1-1: Schematic diagram of abrasive jet micro-machining AJM [4] .............................. 2

Figure 1-2: Schematic of channel blasting apparatus [7] ................................................. 3

Figure 1-3: Schematic diagram of an AJM machine [2] ................................................ 5

Figure 1-4: Change in mass during blasting [2] ............................................................... 7

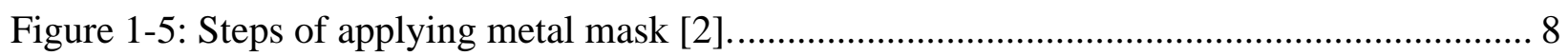

Figure 1-6: Cavitation's effects of different standoff distances [2] ....................................... 10

Figure 1-7: Three stages in the channel shape. Blast lag occurs in stage 2 [5]. ....................... 12

Figure 1-8: Blast lag mechanism and effect of particle size on depth ratio [5]....................... 13

Figure 2-1: 3-D scan result for ductile target material (PMMA) in $300 \mu \mathrm{m}$ width and $25 \mu \mathrm{m}$

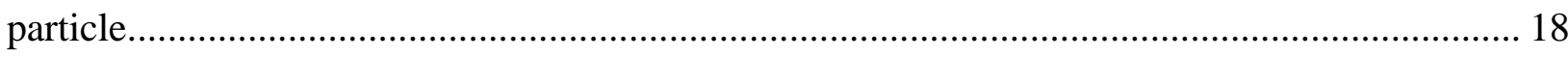

Figure 2-2: Schematic of target for masked AJM experiments. The areas shown in grey were covered with a mask. All channels had a width, w, and the depths $D_{s}, D_{c}, D_{T}$ and $D_{u}$ were measured

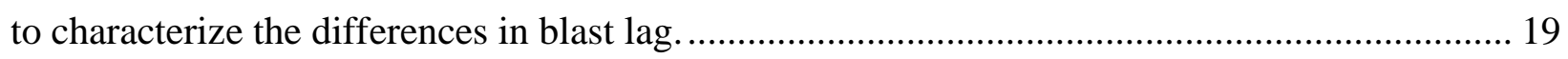

Figure 2-3: Image of mask with $200 \mu$ m wide channels................................................. 19

Figure 2-4: Particle size distribution for nominally $50 \mu$ m particles.................................... 22

Figure 2-5: Particle size distribution for nominally $100 \mu \mathrm{m}$ particles. ................................... 22

Figure 2-6: Profilometer line scans used to obtain depth of cross-intersection and channels leading

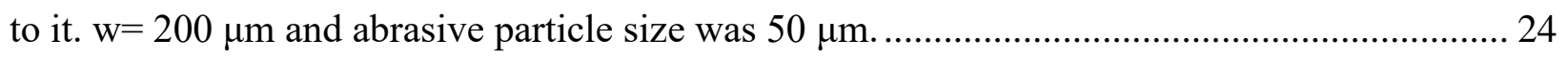

Figure 2-7: Absolute depth ratio of channels and intersections, with respect to unmasked area for

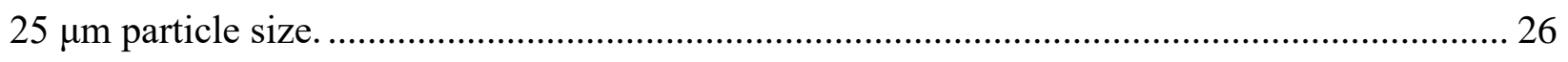

Figure 2-8: Absolute depth ratio of channels and intersections, with respect to unmasked area for

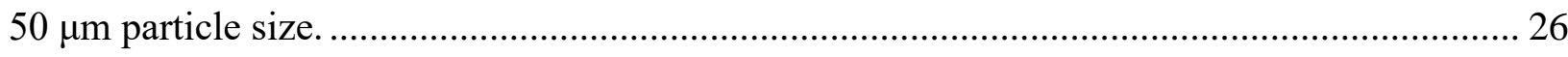


Figure 2-9: Absolute depth ratio of channels and intersections, with respect to unmasked area for $100 \mu \mathrm{m}$ particle size. 27

Figure 2-10: Profiles of channels and center of cross-intersection for $50 \mu \mathrm{m}$ particles and $300 \mu \mathrm{m}$ channel width. 29

Figure 2-11: 3-D profile channels and cross-intersection for $\mathrm{w}=300 \mu \mathrm{m}$ and abrasive particle size of $100 \mu \mathrm{m}$. 29

Figure 2-12: Relative depth ratio between channels and intersections for $25 \mu \mathrm{m}$ particles........ 30

Figure 2-13: Relative depth ratio between channels and intersections for $50 \mu \mathrm{m}$ particles. ........ 31

Figure 2-14: Relative depth ratio between channels and intersections for $100 \mu \mathrm{m}$ particles. ...... 31

Figure 2-15: Profiles of channels and center of cross-intersection for $50 \mu \mathrm{m}$ particle and $550 \mu \mathrm{m}$ channel width. 33

Figure 2-16: 3-D profiles for $550 \mu \mathrm{m}$ channel width and $50 \mu \mathrm{m}$ particle. 33

Figure 2-17: Absolute depth ratio of channels and intersections, with respect to unmasked area for $10 \mu \mathrm{m}$ particle size. 34

Figure 2-18: Relative depth ratio between channels and intersections for $10 \mu \mathrm{m}$ particles. 34 Figure 2-19: 3-D profile of cross-intersection for a channel width of $300 \mu \mathrm{m}$ and abrasive particle size of $10 \mu \mathrm{m}$ 35

Figure 2-20: Predictions of surface evolution model for $200 \mu \mathrm{m}$ wide channel network and 100 $\mu \mathrm{m}$ nominal particle size. The dashed circles represent the largest particle in the distribution (145 $\mu \mathrm{m})$ at the point where blast lag begins in the channels and intersection. The difference in depths shows the maximum difference in blast lag. 39 Figure 2-21: Predictions of surface evolution model for $200 \mu \mathrm{m}$ wide channel network and $50 \mu \mathrm{m}$ nominal particle size. The dashed circles represent the largest particle in the distribution $(75 \mu \mathrm{m})$ 
at the point where blast lag begins. The difference in depths shows the maximum difference in blast lag. 40

Figure 2-22: Predictions of surface evolution model for $200 \mu \mathrm{m}$ wide channel network and $10 \mu \mathrm{m}$ nominal particle size. The dashed circles represent the largest particle in the distribution $(15 \mu \mathrm{m})$ at the point where blast lag begins. The difference in depths shows the maximum difference in

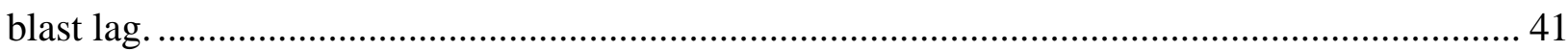




\section{Nomenclature}

$\begin{array}{ll}\alpha & \text { Wall inclination angle } \\ \varphi & \text { Jet angle } \\ E_{w} & \text { Removal rate perpendicular to original surface } \\ E_{b} & \text { Removal rate on the flat bottom } \\ E_{c v} & \text { Erosion classification value } \\ w & \text { Channel width } \\ D_{s} & \text { Depth of sides } \\ D_{c} & \text { Depth of center of cross-intersection } \\ D_{T} & \text { Depth of center of T-intersection } \\ D_{u} & \text { Depth of unmasked area } \\ k_{S} & \text { Absolute depth ratio for sides } \\ k_{c} & \text { Absolute depth ratio for center of cross-intersection } \\ k_{T} & \text { Absolute depth ratio for center of T-intersection } \\ r_{c} & \text { Relative depth ratio for center of cross-intersection } \\ r_{T} & \text { Relative depth ratio for center of T-intersection }\end{array}$




\section{Abbreviation}

$\begin{array}{ll}\text { AJM } & \text { Abrasive jet micro-machining } \\ \text { SPE } & \text { Solid particle erosion } \\ \text { MMR } & \text { Mechanical material removal } \\ \text { JDV } & \text { Jet discharge velocity } \\ \text { AFR } & \text { Abrasive flow rate } \\ \text { MRR } & \text { Material removal rate } \\ \text { PRS } & \text { Pressure regulation system } \\ \text { PAJ } & \text { Pressurized abrasive jets } \\ \text { WFR } & \text { Workpiece feed rate } \\ \text { SPC } & \text { Solid particle composition } \\ \text { SOD } & \text { Stand-off distance } \\ \text { JIA } & \text { Jet impact angle } \\ \text { IAA } & \text { Incomplete attacked area }\end{array}$




\section{Introduction}

This chapter presents a broad overview of the literature relevant to the micro-fabrication on microfluidic devices using abrasive jet micro-machining (AJM). It is meant to provide background and motivation for the objectives of the thesis. A literature survey with a more specific focus on blast lag in micro-channels is presented in Section 2.1.

\subsection{Literature review}

\subsubsection{Constructive solid particle erosion}

Solid particle erosion is damage resulting from the high-speed impact of small solid particles. While it is usually considered as a destructive process, it can also be used in constructive applications, for example for use in fabricating structures in glass, ceramics, and other substrate materials [1]. Techniques as sandblasting and powder blasting are commonly used in mirror and window glass patterning projects, as well as in industrial production works, particularly those requiring two-dimensional designs and entailing superficial erosion [1]. When the target materials have a partial covering of patterned erosion-resistant masks, erosion is localized to the unmasked areas because such coverings are adequately resistant to withstand the solid particle impacts during the mechanical material removal (MMR) process [1,2]. Thus, the resultant solid-particle erosion creates intricate patterns of holes and trenches.

\subsubsection{The abrasive jet micro-machining method}

Like other solid particle erosion (SPE) methods, the abrasive jet micro-machining (AJM) method uses a highly pressurized jet of fluid or gas to carry the abrasive solid particles of a specific range of sizes [2]. A typical setup is shown in Figure 1-1. To make very small features $(<1 \mathrm{~mm})$, AJM requires the use of an erosion-resistant mask to protect the substrate material, while leaving out the exposed areas as the areas for machining. AJM has been used to make a number of microfluidic devices. For example, Solignac et al. [3] used AJM and a metal mask with $100 \mu \mathrm{m}$ wide openings to fabricate $30 \mu \mathrm{m}$ deep microfluidic channels to form a capillary electrophoresis chip [4]. 


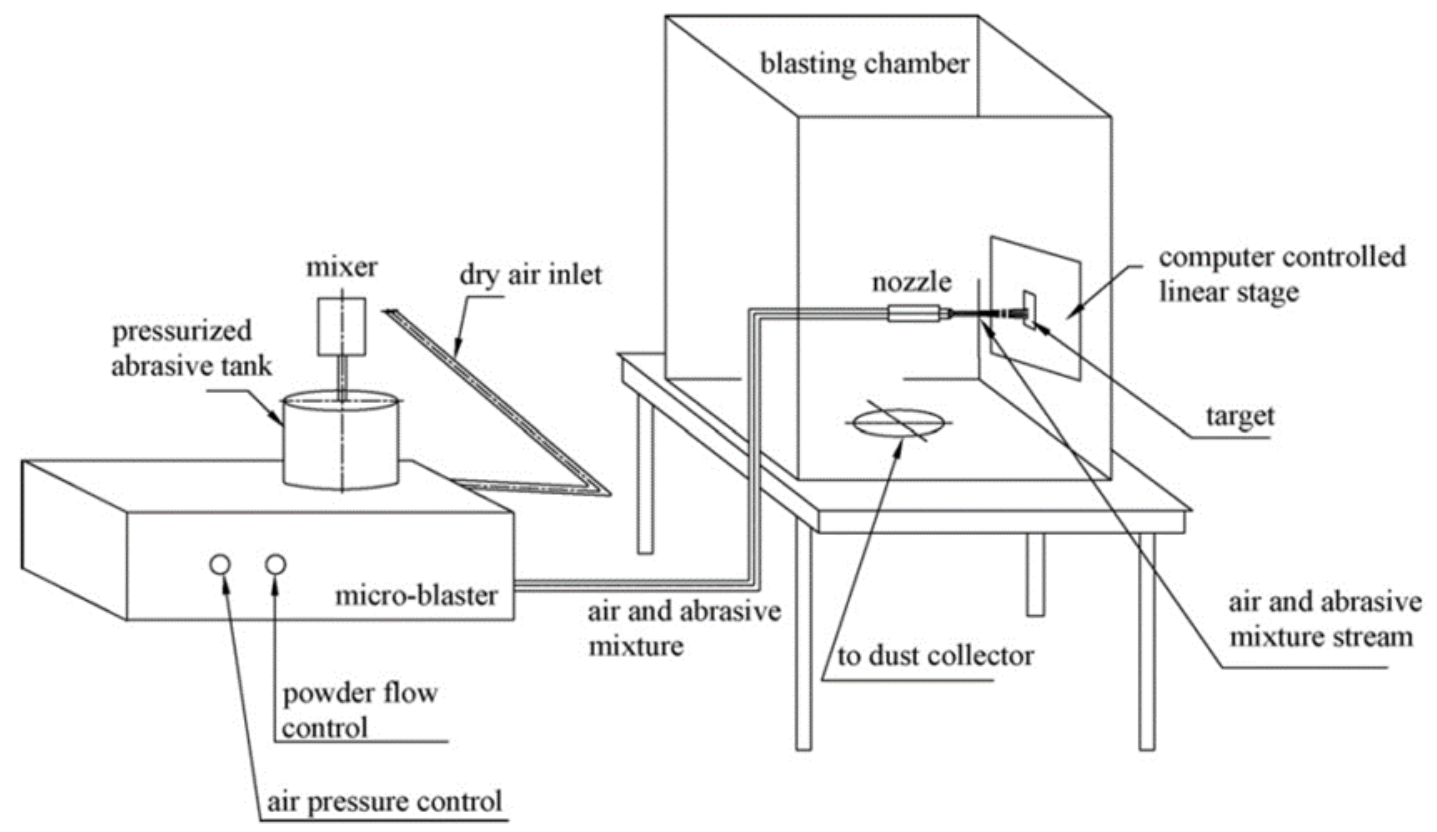

Figure 1-1: Schematic diagram of abrasive jet micro-machining AJM [5] .

The AJM method, however, has some drawbacks. First, the powder blasting process generates rough surfaces on the cut surfaces, often an unwanted adverse effect [6]. Second, if the target material is ductile, the abrasive particles have a tendency to become embedded. Thus, with such a characteristic, this method is essentially a bulk, industrial, micro-machining technique. Third, the eroded features do not usually conform to the border of the mask, causing an imperfectly eroded structure. However, even granting that certain abrasive particles hit these surfaces, it is likely that the mask border itself can obstruct the surface contact, decelerating the abrasive particles or diverting them from their original path. Thus, the MMR rate is expected to decline towards the mask border, creating a slanted sidewall [6].

Features can be made using AJM on substrates that are either masked or unmasked. For relatively small features, masked micro-machining (Figure 1-2) must be used, and one might expect that the erosion rate across most of the channel will be relatively constant. However, as mentioned above, at the feature edge, there will be an interaction between the particles and the edge of the mask, and the erosive influence will be reduced. For unmasked features, the erosive influence is non-uniform due to gradients in the particle velocity and flux [4,7]. 


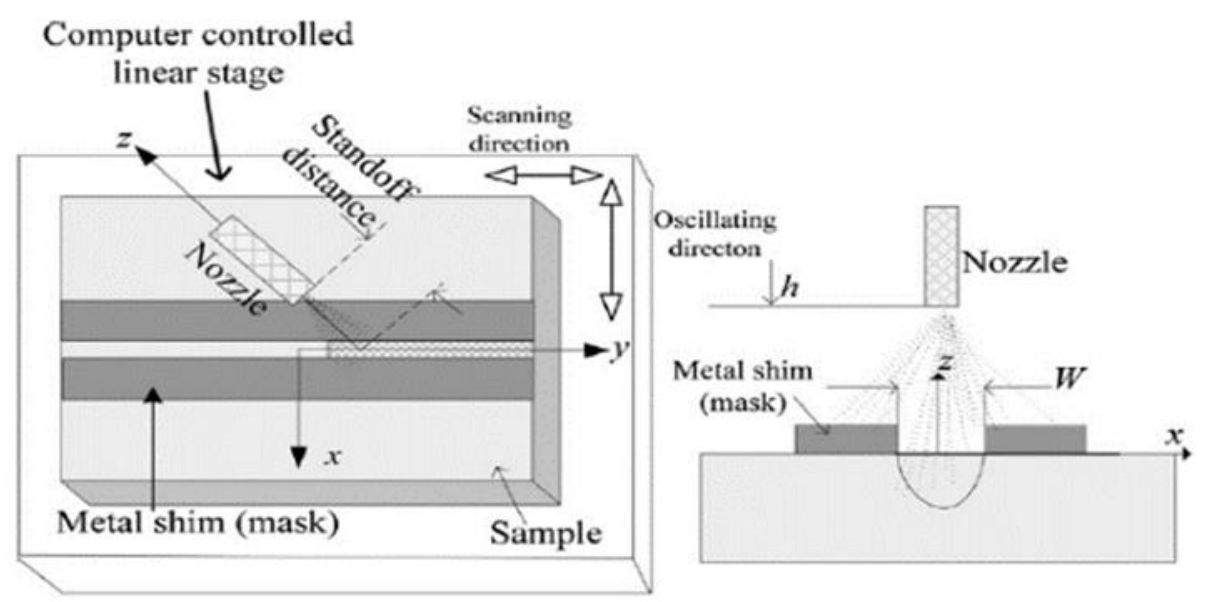

(a)

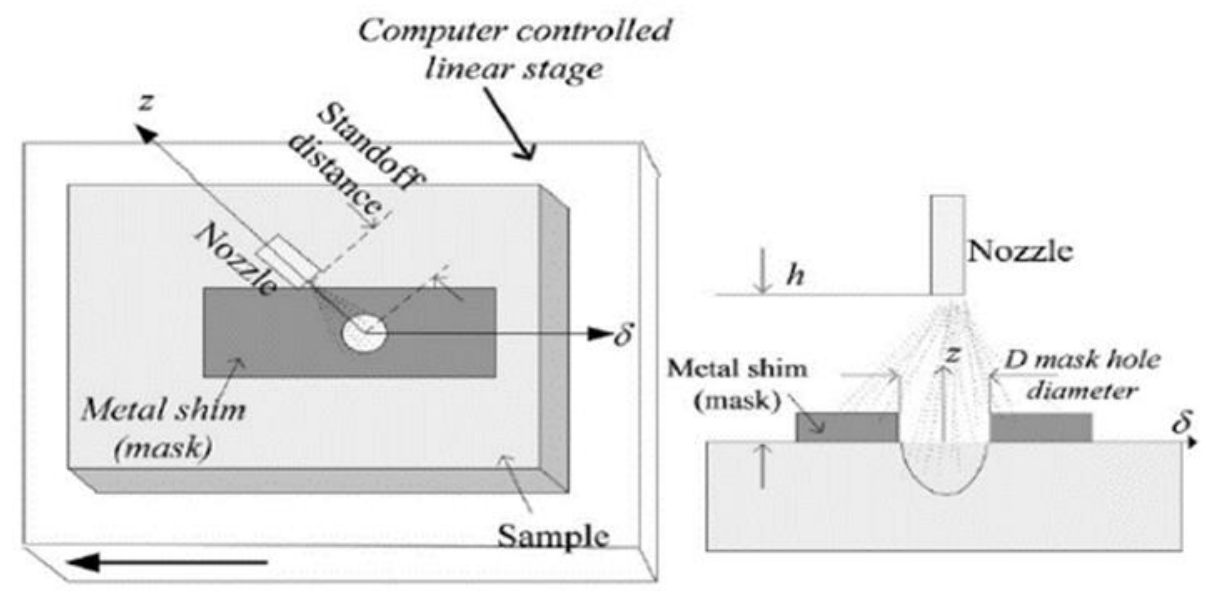

(b)

Figure 1-2: Schematic of channel blasting apparatus [4].

\subsubsection{The abrasive solid particles}

In the AJM method, the abrasive solid particles have an average diameter of 10 to $100 \mu \mathrm{m}$ [2]. They must be large enough to cause meaningful and predictable erosion on the substrate material but must be fine enough to stay suspended in their carrier gas and pass within the mask opening and reach narrow and fine areas. The particles must be sharp and of irregular shapes to ensure a better erosion performance.

The choice of a specific particle, however, depends on the machining operation to be performed [2]. There are four commonly used abrasive materials in the AJM method: aluminum oxide $\left(\mathrm{Al}_{2} \mathrm{O}_{3}\right)$, silicon carbide $(\mathrm{SiC})$, sodium bicarbonate $\left(\mathrm{NaHCO}_{3}\right)$, and glass beads. Aluminum 
oxide is most often used at a particle size range of 3 to $30 \mu \mathrm{m}$ [6]. Aluminum oxide, silicon carbide, and sodium bicarbonate are used for cleaning as well as machining [2], while glass beads are used for surface finishing and reducing roughness.

\subsubsection{The abrasive flow rate}

The typical abrasive particle velocity is approximately $100 \mathrm{~m} / \mathrm{s}$ [8]. The mechanical material removal (see section 2) usually increases with both the abrasive velocity the abrasive mass flow rate (AFR), but only up to a certain limit, after which the MRR starts declining [2]. This can occur because of collisions between incoming and rebounding particles [9]. The direct relationship between AFR and MRR can be explained by the direct relationship between AFR and the number

of abrasive particles discharged from the nozzle and, thus, hitting the substrate material, consequently, increasing the MRR.

\subsubsection{The carrier gas}

The AFR is driven by the carrier gas, which is either carbon dioxide, nitrogen gas, or air. The primary consideration in selecting a carrier gas is its inability to flare, or at least not excessively so, when discharged from the nozzle. Of the commonly used carrier gases, air, however, is considered the most preferable because of its universal accessibility, its zero toxicity, and its zero-acquisition cost [2].

\subsubsection{The nozzle material}

Nozzle selection must comply with specific characteristics, such as:

(a) Supersonic air flow velocity in the nozzle.

(b) Ability for homogeneous dispersion of abrasive particles over its width; and

(c) Long lifetime and erosion resistance.

Jain [2] noted that the most commonly used nozzle material for AJM is tungsten carbide or sapphire. 


\subsubsection{AJM equipment}

A typical AJM setup is shown in Figure 1-3, consisting of five major parts: the compressor; the pressure regulation system (PRS); the abrasive powder feeder (APF); the mixing chamber; and the nozzle [2]. The compressor, which contains a pressure relief valve, an air filter cum drier, and a pressure drain, conducts compressed pressure through the PRS into the mixing chamber. The PRS consists of a pressure regulator, an opening valve, and a pressure gauge.

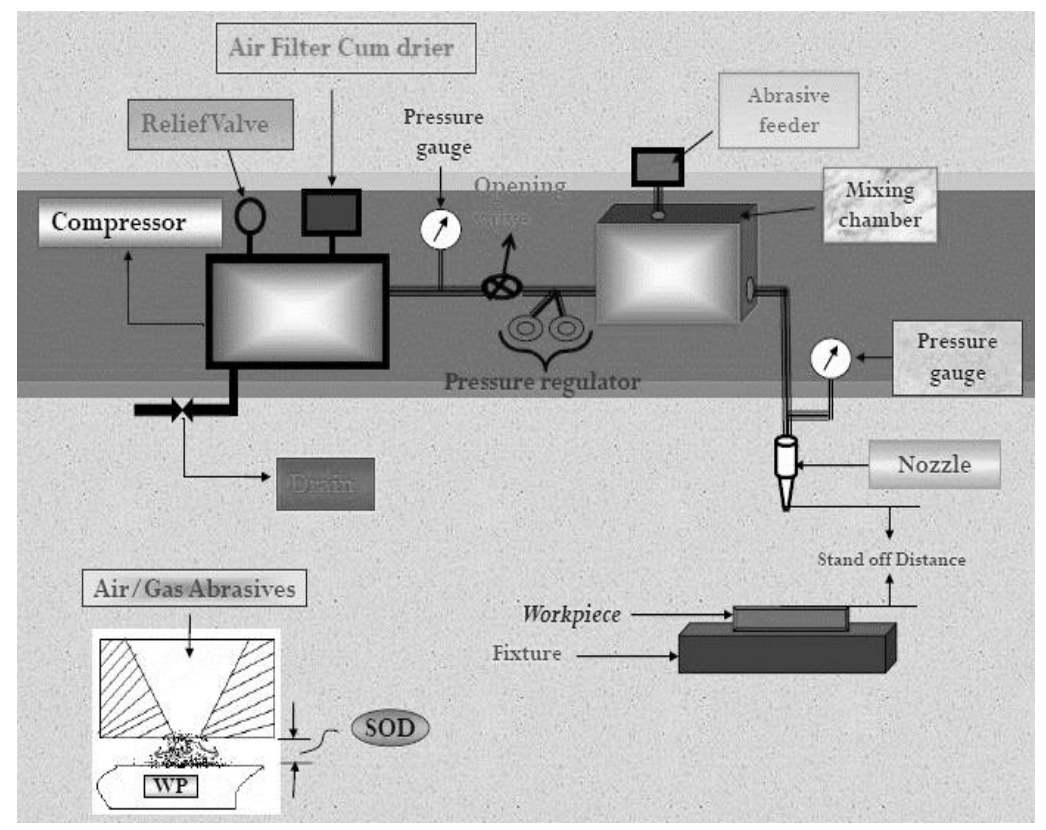

Figure 1-3: Schematic diagram of an AJM machine [2]

The ABF, attached to the mixing chamber, delivers a controlled volume of abrasive solid particles, often recorded as a powder per unit time [6], into the mixing chamber. The mixing chamber effectively mixes the abrasive particles and the carrier gas under a compressed pressure inside. The automated nozzle control regulates the pressurized abrasive jet coming from the mixing chamber, which is monitored through the pre-nozzle pressure gauge. The jet emerges with a welldefined powder volume to ensure a homogenous particulate exposure and erosive wear on the substrate fed through a blasting chamber $[1,6]$. The blasting chamber is ventilated, usually in a circular airflow, to separate the particles and the airflow through the exhaust [6]. 


\subsubsection{Comparison with traditional micro-machining methods}

The AJM method differs significantly from the conventional micro-fabrication methods available today, such as wet etching and dry etching. First, it is capable of fabricating anisotropic patterns and suspended structures [2]. Second, it has inherently a higher erosion rate. Third, it has a relatively low associated cost, and fourth, it is capable of machining multiple depths in a substrate, unlike chemical etching, which creates depth at a constant rate over the entire substrate [2]. On the other hand, the MRR is rather low on ductile targets which are also subject to increased levels of particle embedding.

\subsection{The masking technology}

The utilized masks must be erosion resistant, as consistent as possible with the perfect erosion resistant theory, which assumes that no interaction occurs between the mask and the abrasive powder. The theory also assumes a mask in a state of infinite thinness. Practice, however, indicates that the mask slowly erodes during the fabrication process and that typical mask thickness of 50 to $100 \mu \mathrm{m}$ are used [1].

Elastomers and metals are inherently highly resistant to powder blasting in the AJM method, making them useful materials as masks [6]. The quality of mask material usually determines the maximum channel depth that can be attained during powder blasting [6].

One of the most import factors that affect the performance of AJM is the quality of the mask, i.e. the lower its erosion rate, the better its quality. The other qualifications for a good mask are its ability to execute an accurate and easy pattern transfer and the capability to hold their resistance in discontinuous layers [2]. As shown in Figure 1-4, commonly used mask materials divide into three different categories. The first group is ductile materials such as metals. The second category is elastic materials such as elastomer and third group are photo-resist masks as used in the integrated circuit industry [2]. It is important to mention that the erosion resistance of the masks depend on the angle of attack, with ductile materials showing the most resistance at perpendicular incidence, and brittle materials at oblique ones. 

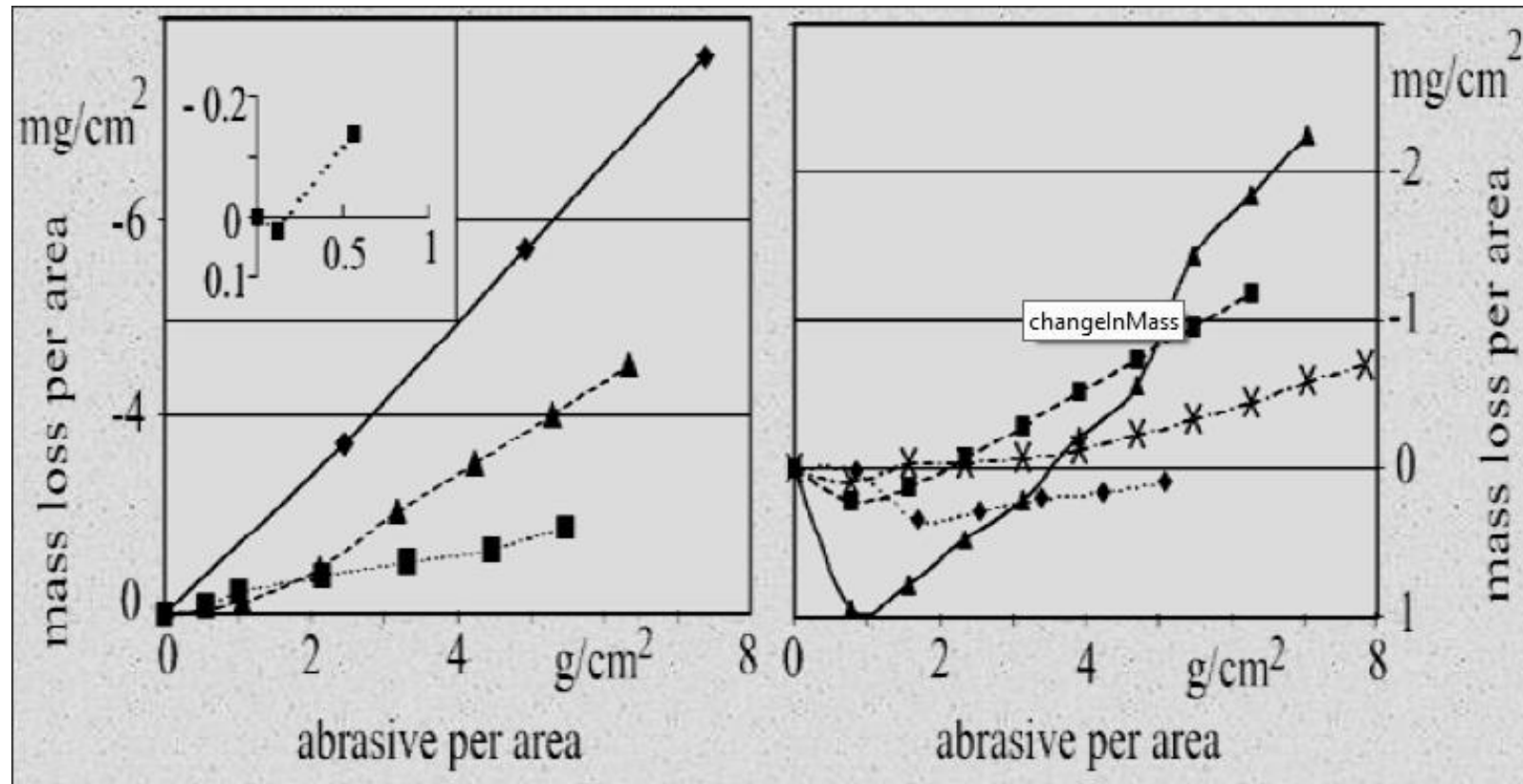

$\triangle$ Copper

- Stainless steel

- Zinc blasting

pressure $0.2 \mathrm{MPa}$
- UltraPro

$\times$ Rayzist
- ImagePro

\ RapidMask

Figure 1-4: Change in mass during blasting [2].

\subsubsection{Metal Masks}

One of the most suitable mask materials for AJM is metal, which are considered as ductile erosive having a low erosion rate at perpendicular impact angle. There are two ways to apply metal mask plates for AJM. It can be directly clamped to the target or it can be done by introducing a coating layer which can be patterned using lithographic methods. In addition, to use the mask on several targets, it is necessary to use a thick metal layer. On other hand, this type of mask has some disadvantages such as limitation on feature size (approximately $50 \mu \mathrm{m}$ ) [2].

To have high resolution during the lithographic process electroplating can be used. For instance, copper masks are often applied using this technique. Zinc masks can be made by electroforming. There are six steps for applying copper mask, see Figure 1-5. The first step is the whole target is enclosed in a titanium $(15 \mathrm{~nm}) /$ copper $(400 \mathrm{~nm}$ ) layer works as an intermediate protection layer [2] between the target and the copper. The second step is applying a thick polymer foil used 
with electroplating as a mould in which the copper is grown. Photolithographically defining the micro pattern is the next step and because of that the target is plated with copper. Photolithography is a useful technology in accurately defining complex designs [3], which is difficult to achieve in manual designing techniques. Thus, photolithographic techniques are standard in the AJM and other micro-machining methods. The photolithographic technique can achieve a minimum feature size of approximately $30 \mu \mathrm{m}$, which is an adequate micro-size for industrial bulk micro-machining works [3]. Due to the directionality of the AJM method, aspect ratios of not more than 2.5 are attainable. After patterning, a $10 \% \mathrm{KOH}$ solution at room temperature is used to remove the polymer. Finally, the thin seed layer is easily etched away during the blasting. A strong acid such as $\mathrm{HNO}_{3}$ can help to remove the remaining copper after blasting [2].

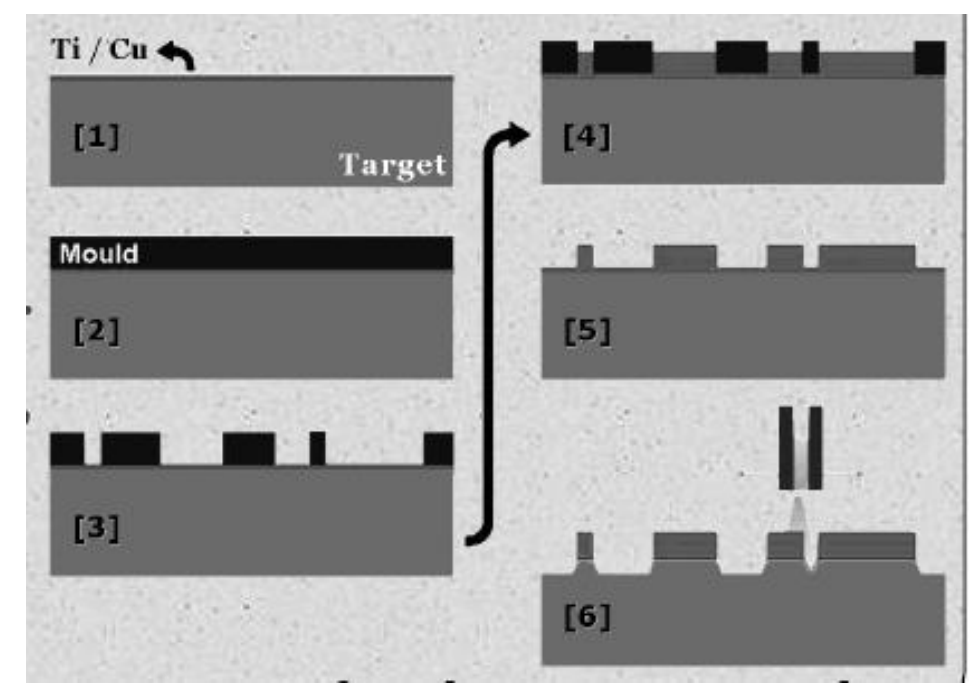

Figure 1-5: Steps of applying metal mask [2]. 


\subsubsection{Elastomeric Mask}

The erosion mechanism of rubber-like materials such as elastomers diverges mainly from the brittle material or ductile materials. The advantage of an elastomeric mask is its very high erosion resistance since the erosion mechanism of this material is based on fatigue. In addition, photosensitive elastomer can be effective since the material can be patterned accurately using photolithography. The elastomer mask wear depends on temperature, rate of deformation, and particle velocity. Depending on the relevant practical conditions, the elastomers can show ductile, elastic and brittle behavior [2].

\subsubsection{Photo-resist Mask}

Photo-resist masks are a kind of photosensitive material that divide into two types. The first type is a positive resist such as Image Pro where the material to be removed is exposed to ultraviolet (UV) light. Exposure to the UV light transforms the chemical structure of the resist, making it easily soluble in the developer. The second type of photo-resist mask is a negative resist which acts in the opposite manner of positive resist such as SU-8 which is able to provide features with high aspect ratios (more than 10) with UV lithography [2].

\subsection{Material removal mechanisms}

\subsubsection{The micro-machining mechanism}

When the pressurized abrasive jet is actuated, the abrasive particles hit the exposed surfaces of the workpiece substrate, and accumulation of damage results in removing material at different rates according to the gradient in abrasive flux and velocity reaching the surface. The width of the formed cavity in an unmasked application is generally equal or larger than the nozzle diameter because of the divergence of the jet plume [2]. As shown in Figure 1-6, the dimension of the substrate cavity varies, however, with changes in the nozzle standoff distance (or nozzle tip distance), which can be manipulated manually. As Jain [2] explained, the cavity size increases with the increase in the standoff. 


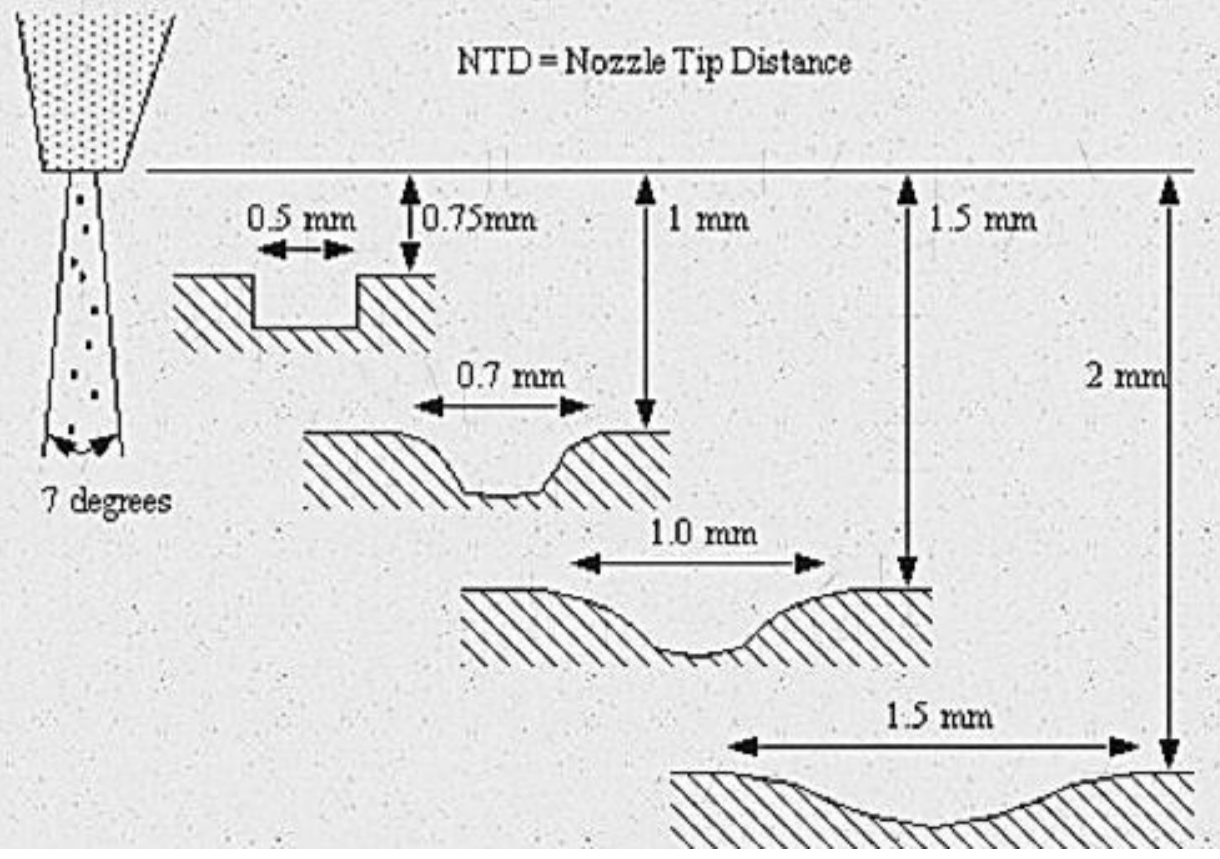

Figure 1-6: Cavitation's effects of different standoff distances [2]

The cavity depth can vary with the workpiece feed rate (WFR) or scan speed; the abrasive particle mass flux, and the jet pressure which affects the particle velocity. The erosion literature demonstrated interesting behaviors of the abrasives in relation to the exposed substrate. Jain [2] observed that, as the abrasive particles hit the substrate surface, they cause minute fractures on it, while the gas stream carries away both the abrasive particles and the fractured particles. Slikkerveer and Veld [1] noted that, for brittle materials, the erosion efficiency is highest at a perpendicular angle of incidence. Theoretically, the MMR depends on three properties of the substrate material, i.e., the fracture toughness, hardness, and elastic modulus, and on the kinetic energy of the abrasive particles [6]. Wensink and Elwenspoek [6] noted that glass and silicon carbide abrasive powders can achieve an MMR rate of $25 \mu \mathrm{m} / \mathrm{min}$ using sharp alumina particles (size $29.2 \mu \mathrm{m}$ ), an air pressure of 4.5 bar (particle speed of approximately $220 \mathrm{~m} / \mathrm{s}$ ), and a powder flux of $10 \mathrm{~g} / \mathrm{min}[6]$.

Abrasive particles that manage to retain some energy after their first impact tend to rebound from steep walls [1]. They can generate additional erosion proximate to the pattern center, causing the dimpling of the cavity walls. This occurs because of the increased impact angle for the second impact. Similarly, as the dimpled walls develop at greater depths, the erosion speed tends to decrease with the erosion depth. 


\subsubsection{Brittle erosion}

Slikkerveer and Veld [1] demonstrated that the erosion rate (i.e. the ratio of the mass of removed substrate material to that of the impacting abrasive) of brittle substrates when struck by hard and sharp micro particles is directly proportional to the normal component (i.e., perpendicular to the surface) of the abrasive particle velocity, modified by the particle size. Thus, evidently, brittle erosion is most efficient at normal incidence of the abrasive with a lower erosion rate at oblique incidence. This characteristic of brittle erosion, results in the highest MMR in the middle of the machined feature where the particle impacts are perpendicular to the surface, and a lower MMR rate on the side walls, which result in lower local impact angles [6]. All brittle substrates, such as silicon and glass, exhibit this erosion characteristic. For the machining of micro-channels, their formation appears to follow three stages (Figure 1-7):

(1) The bowl shape stage, which has a flat central section and slanted walls in either side;

(2) The V-shaped stage

(3) The convex-concave shape stage, which resulted from the second impacts of particles (i.e. those retaining some erosive energy after their first impact).

When the channel reaches the third stage, any further particle impact on the side walls at a small angle of impact, will result only in a decreased MMR rate. However, if the mask opening is large, this point of decline in MMR occurs much later and at a deeper level. A decrease in MMR rate can also occur in stage 2 due to a 'blast lag' effect (explained below), which makes it harder to reach high aspect ratios [6]. The continuing decline in the MMR in this stage disproportionately strains the mask material, making the mask material quality important in limiting the maximum depth a channel can reach. 


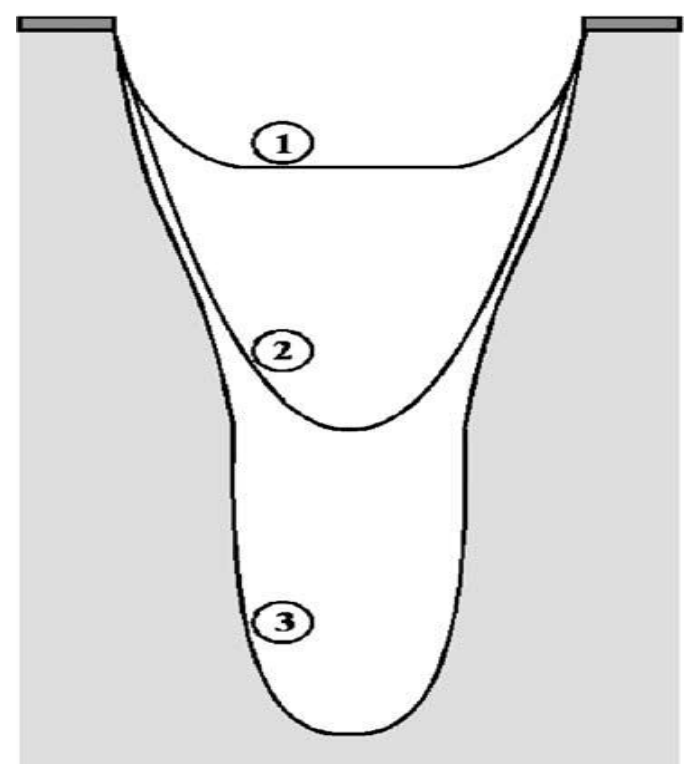

Figure 1-7: Three stages in the channel shape. Blast lag occurs in stage 2 [6].

\subsubsection{Ductile erosion}

Ductile substrates, such as aluminum, exhibit two types of mechanical changes when exposed to abrasive solid substances. First, these substrates may exhibit surface hardening because of the repetitive deformation that the particle impacts caused [2]. Second, surface cracking also can be observed, often as a result of the hardening. The key difference between brittle and ductile erosion is the fact that while brittle erosion is maximum at perpendicular incidence, ductile erosion is maximum at oblique incidence. This causes machined features to rapidly develop very steep sidewalls. 


\section{$1.4 \quad$ Blast lag}

\subsubsection{Effect of material}

When machining channels, their formation is significantly dependent on the substrate material unprotected with the mask. Wensink and Elwenspoek [6] explained that, for brittle materials, this is so because of the role of the sidewall inclination in creating a 'blast lag' wherein, unlike smaller channels, wider channels tend to become deeper during powder blasting At stage 2 (Figure 1-7), this results in a decline in the MMR, making it harder to achieve high aspect ratios. It mainly occurs because the area in the center of the channel at the bottom of the V-shape that forms in stage 2 , becomes so narrow that the largest abrasive particles cannot reach the center, as depicted in Figure 1-8. For ductile materials, such an effect is not present because the sidewalls rapidly become steep due to the increased erosion rate at the locally oblique incident angles.

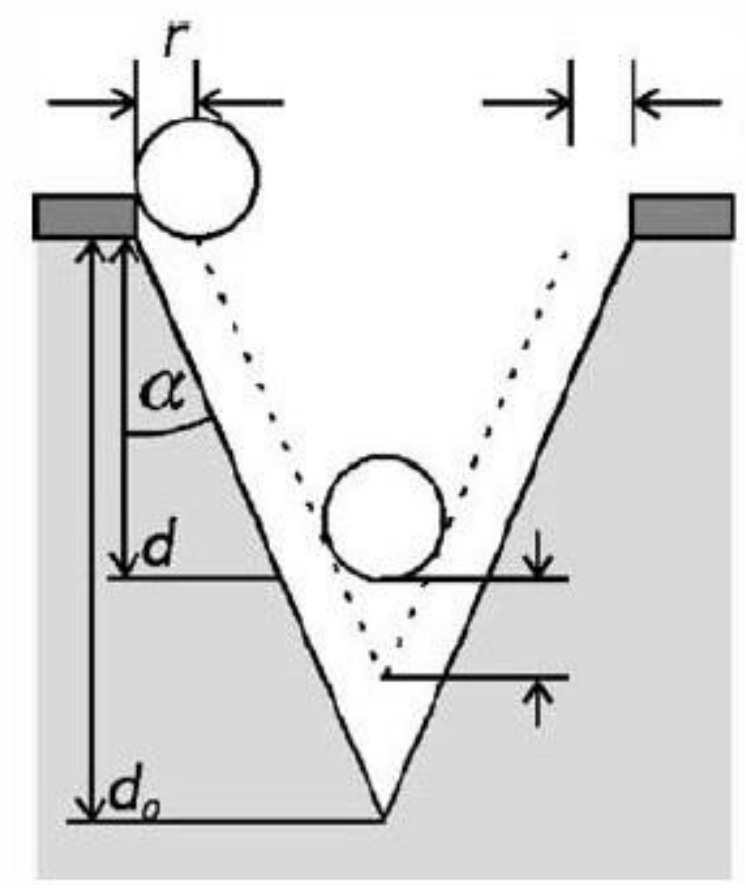

Figure 1-8: Blast lag mechanism and effect of particle size on depth ratio. Blast lag defined as $d_{0}-d[6]$. 


\subsubsection{Effect of abrasive particle size}

Blast lag in micro-channels is directly related to the size of the abrasive particles. This is so for two established reasons:

(1) Particle size is directly related to the channel cross-section depth;

(2) Particle size affects their ability to reach narrow areas in the channel center.

\subsubsection{Effect on the access of narrow areas along the center of the channel}

The size of abrasive particles is directly related to its ability to access narrow open areas along the center of channel. The smaller the particle size, the greater access it has on these open areas compared to larger particle sizes [6]. Due to this increased access to narrow open areas along the center of V-shaped channel, smaller particles can deliver sharper erosive performance and, consequently, deeper and V-shaped channel. This performance inevitably results in a decline in the blast lag. While larger particles increase its erosive effect in larger channels, this effect applies only for channels in the stage 2 cross-section [6].

\subsubsection{Effect on the erosion near the mask edge and relation to sidewall steepness}

The size of the eroded region along the mask border depends on the abrasive particle size [6]. The smaller the particle size, the closer the particles can strike the edge, resulting in wider channels. In wider channels, the two sidewalls take a longer time to meet at the bottom of the channel than in smaller channels, resulting to a reduced blast lag. Conversely, in smaller channels, the increase in channel width is effectively larger. 


\subsection{Motivation}

The thesis is motivated by the following:

i. All previous research regarding blast lag involved the machining of single, straight channels. In reality, however, most microfluidic chips involve networks of channels. It was hypothesized that the blast lag in channel intersections might differ from that in channel sections, since intersections are effectively wider than channels.

ii. Differences in blast lag in channels and their intersections may lead to undesirable flow effects in microfluidic devices.

iii. There is no model currently available to predict the propensity for blast lag to occur in either channels or intersections of channels.

\subsection{Objectives}

The overall objective of the thesis was to measure and model the relative amounts of blast lag at various points in networks of microfluidic chips machined using AJM. Secondary objectives designed to meet this overall goal include:

i. Determine and compare the absolute blast lag (i.e. relative to an infinitely wide unmasked channel) in a microfluidic channel network containing different channel widths using different particle sizes. The network will contain both cross-intersections and Tintersections of channels.

ii. Determine and compare the relative blast lag between channels and both T-intersections and cross-intersections to thus quantify local changes in depth.

iii. Suggest solutions to reduce absolute and relative blast lag.

iv. Develop a model to predict the onset of blast lag for both channels and intersections. 


\section{Measurement and modeling of blast lag in a micro-channel network}

This chapter focuses on the measurement and modeling of blast lag in a chosen representative microfluidic network containing both $\mathrm{T}$ and cross-intersections. It is based on the following submitted paper (currently under review): Soheil Shafagh, Marcello Papini, the effects of blast lag in abrasive jet machined micro-channel intersections.

\subsection{Introduction}

Abrasive jet micro-machining (AJM) uses a highly pressurized fluid such as nitrogen or air to create a high-speed jet containing abrasive solid particles which is used to remove material from a target [6]. It is often referred to in the fabrication literature as powder blasting due to its standard use of fine, hard, and solid abrasive particles, often in powdered physical form [6]. Removal of materials from brittle targets such as borosilicate glass occurs due to the high-speed particle impacts, forming lateral cracks which propagate to the surface, thus removing chips of material [6]. Since the abrasive jet spreads in an approximately conical manner, when micromachining e.g., microfluidic chips $[5,10,11]$ patterned masks are commonly applied to the target surface to control the area to be machined. The AJM method differs significantly from conventional micro-fabrication methods such as wet etching and dry etching. Unlike these traditional methods, it can rapidly etch directionally and in an anisotropic fashion, so that, e.g., three-dimensional suspended structures and features at multiple depths can be easily machined into a given substrate $[6,12,13]$.

AJM, however, has some notable drawbacks. The roughness of the machined surfaces is often high, and, for certain applications, post-processing such as acid etching [10,14] or postblasting with smaller particles [10,14] is required to smoother the surface [11]. Another potential drawback is that, for the same incoming particle dose, narrower micro-channels and micro-holes machined using AJM on brittle materials have been reported to be shallower than wider ones. This phenomenon is commonly referred to as 'blast lag' [6], and can make prediction of the machined depth difficult. Initially, the hole or channel (machined feature) cross-intersection is flat bottomed and bowl-shaped, but as the dose of particles increases and the feature becomes deeper, the sidewalls meet at the centre, resulting in a more V-shaped feature [6]. Surface evolution models 
have been developed to predict the evolving shape of the feature up to this point [7,15-17]. Once the $\mathrm{V}$-shaped channels are formed, some of the larger particles incident to the centreline are prevented from striking the narrow space adjacent to the vertex at the bottom. Since a wider feature requires a larger particle dose in order for the transition to a $\mathrm{V}$-shape to occur, wider features will be deeper than narrower ones at the same particle dose. This blast lag effect thus manifests as a drop in the effective etching rate at a certain depth. It is usually characterized as the depth of a feature machined using a mask opening of a given width relative to the depth of a (much wider) unmasked feature machined under identical conditions [6].

Blast lag occurs only in brittle erosive systems, where the V-shaped channel rapidly results because the erosion rate is higher at normal incidence (flat channel centre) compared to on the sloped sidewalls $[6,15,18]$. For ductile erosive systems as it shown in Figure 2-1, the much higher erosion rate at oblique incidence (channel sidewalls), compared to normal incidence (channel centre) results in a U-shaped cross-intersection which is not subject to the blast lag phenomenon [6]. Wensink and Elwenspoek noted that blasting with the jet oblique to the target can reduce blast lag in straight channels or holes since the material removal rate on the flat feature bottom is decreased relative to the sidewalls, thus extending the "stage I" erosion when the feature remains bowl shaped [6]. The net result of blasting across a feature at oblique incidence is that a more Ushaped feature results, which is less prone to blast lag.

The dependence of blast lag on feature width and particle size has been previously reported and characterized for simple straight channels and holes [1,6]. For the first time, this thesis reports how differences in blast lag can cause problems in the machining of more complex networks of intersecting channels, all having the same width, and all subject to the same particle dose. In addition, a surface evolution model was used to show the onset of the differences in blast lag, and to propose possible solutions that minimize these effects. The results have important implications for the AJM of microfluidic devices that contain such networks. 


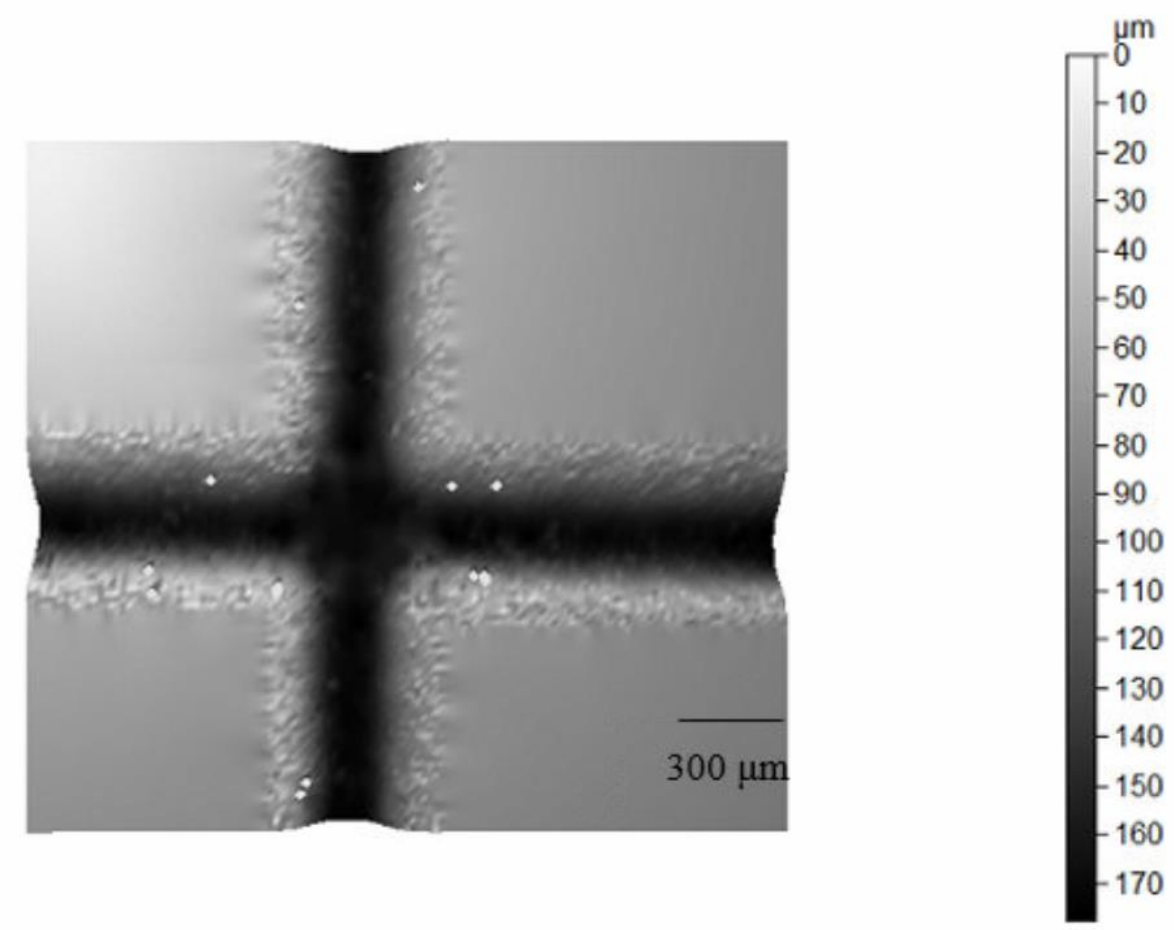

Figure 2-1: 3-D scan result for ductile target material (PMMA) in $300 \mu \mathrm{m}$ width and $25 \mu \mathrm{m}$ particle.

\subsection{Experiments}

The differences in blast lag in various channels and intersections were compared by machining the network of masked channels shown in Figure 2-2 and

Figure 2-3. The channel widths $w$, in a given experiment were constant, and the configuration allowed direct comparison, under constant particle dose, of the machined depths of masked channels, unmasked channels, T-intersections, and cross-intersection. 


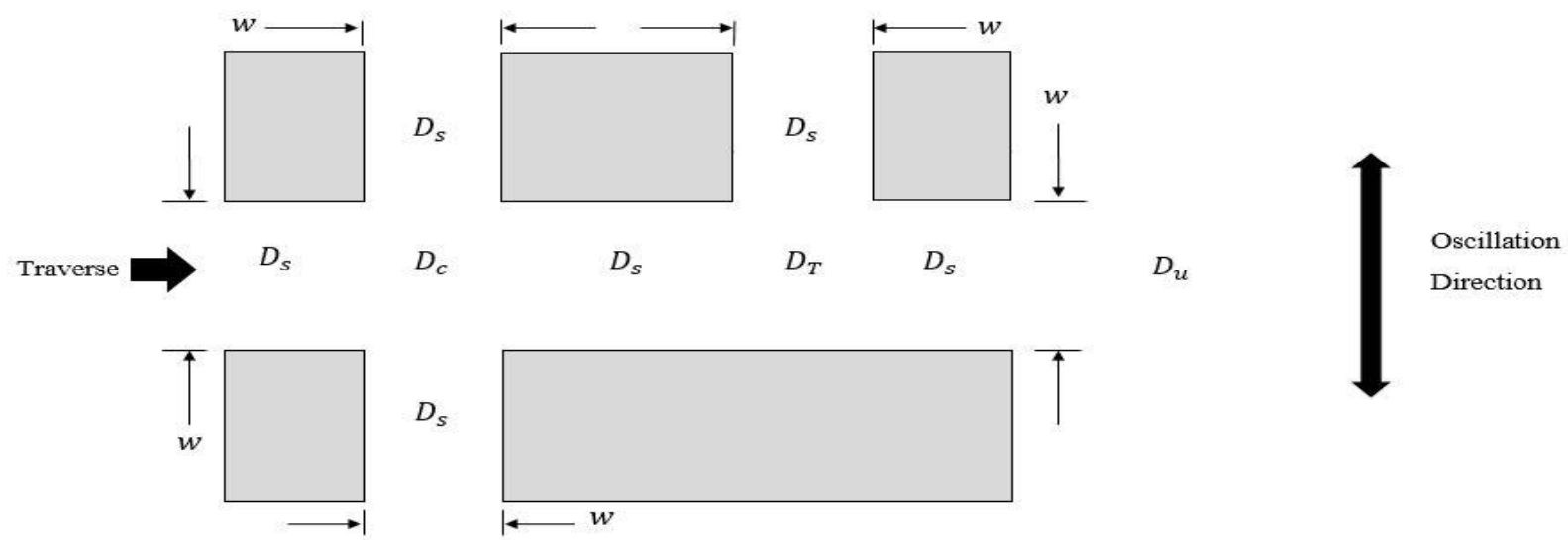

Figure 2-2: Schematic of target for masked AJM experiments. The areas shown in grey were covered with a mask. All channels had a width, w, and the depths $D_{s}, D_{c}, D_{T}$ and $D_{u}$ were measured to characterize the differences in blast lag.

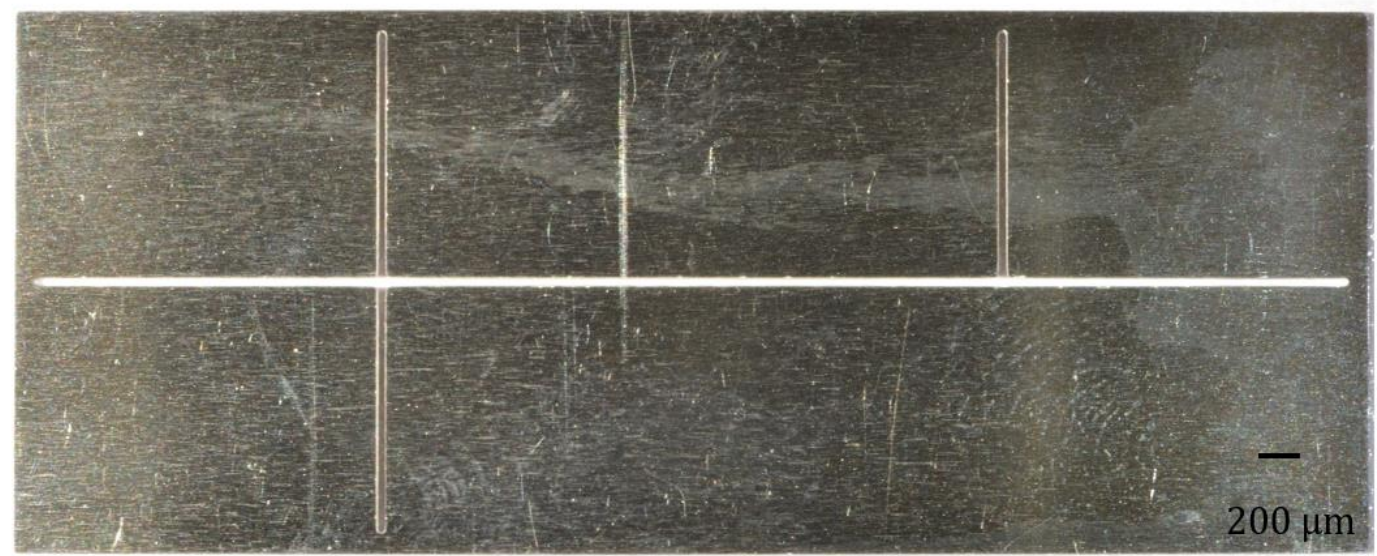

Figure 2-3: Image of mask with $100 \mu \mathrm{m}$ wide channels. 


\subsubsection{Machining setup and materials}

The effect of particle size on blast lag differences within the network of micro-channels was investigated by blasting angular alumina powder possessing nominal particle sizes of 10, 25, 50 and $100 \mu \mathrm{m}$ on $100 \times 50 \times 3 \mathrm{~mm}$ thick borosilicate glass (Borofloat, Swift Glass Co. Inc., Elmira, NY, USA) samples covered with stainless steel masks patterned according to Figure 2-2. Figure 2-4 and Figure 2-5 show examples of the particle size distributions which were either normal or log-normal (Table 2-1). The masks were patterned using photoetching by a local supplier (Shimifrez, Vaughan, Ontario, Canada), and taped to the Borofloat samples. A portion of the sample was left unmasked so that measurements of machined depth on an unmasked target could be simultaneously obtained. Since blast lag is a strong function of channel width [6], three stainless steel masks with mask openings, $w$, of 100, 200 and $300 \mu \mathrm{m}$ were used with corresponding thicknesses of 150,250 , and $350 \mu \mathrm{m}$, respectively. The use of different mask thicknesses was related to the dimensional tolerances of the photoetching procedure which demanded that the minimum mask opening dimensions be less than 10-15\% of the mask thickness. The choice of mask opening widths is consistent with a typical range for many microfluidic applications [19].

As in previous AJM studies, an air pressure of $200 \mathrm{kPa}$ was used [6,17,20]. The samples were blasted using an AccuFlo AF10 micro-abrasive blaster (Comco, Inc. Burbank, CA, USA) which was fitted with rectangular nozzles of different sizes (depending on the particle size, Table 2-1) at a $20 \mathrm{~mm}$ standoff distance between the nozzle exit and target. The abrasive mass flow rate range was between $6.2-12.4 \mathrm{~g} / \mathrm{min}$ and the estimated particle velocities at the nozzle exit calculated using the model of Li et al. [21] are shown in Table 2-2. This model has been previously experimentally verified for the same blasting apparatus under similar process conditions [22]. Using a computer-controlled stage, the target was oscillated laterally at a $10 \mathrm{~mm}$ amplitude with a $1 \mathrm{~Hz}$ frequency while traversing at $2 \mathrm{~mm} / \mathrm{s}$ (Figure 2-2). This oscillation technique has been used previously in a number of AJM studies to ensure that the total particle dose to any point on the sample is constant [23]. To ensure that all channels were sufficiently deep such that a V-shape channel formed (stage II according in Wensink [6]), 10 such oscillating traverses were performed. Each experiment at a given set of conditions in Table 2-2 was repeated three times to assess the scatter. After each experiment, the width of the mask openings was measured to ensure that they did not erode sufficiently to widen the openings. 
Table 2-1: Abrasive particle distribution

\begin{tabular}{|c|c|c|c|c|}
\hline Particle size $(\mu \mathrm{m})$ & $10^{*}$ & $25^{*}$ & 50 & 100 \\
\hline Type of distribution $(\mu \mathrm{m})$ & Log - Normal & Log - Normal & Normal & Normal \\
\hline Mean of radii $(\mu \mathrm{m})$ & 5.9 & 10.2 & 22.7 & 42.6 \\
\hline Standard deviation $(\mu \mathrm{m})$ & 3.1 & 5.5 & 4.2 & 4.8 \\
\hline
\end{tabular}

* Data from [24]

Table 2-2: Process parameters used for AJM experiments.

\begin{tabular}{|c|c|c|c|c|}
\hline Particle size $(\mu \mathrm{m})$ & 10 & 25 & 50 & 100 \\
\hline Nozzle size $(\mathrm{mm})$ & $0.2 \times 1.5$ & $0.2 \times 1.5$ & $0.2 \times 3.2$ & $0.3 \times 3.8$ \\
\hline Estimated particle velocity $(\mathrm{m} / \mathrm{s})$ & 197 & 149 & 120 & 93 \\
\hline Channel width, $w(\mu \mathrm{m})$ & \multicolumn{4}{|c|}{$100,200,300$} \\
\hline
\end{tabular}




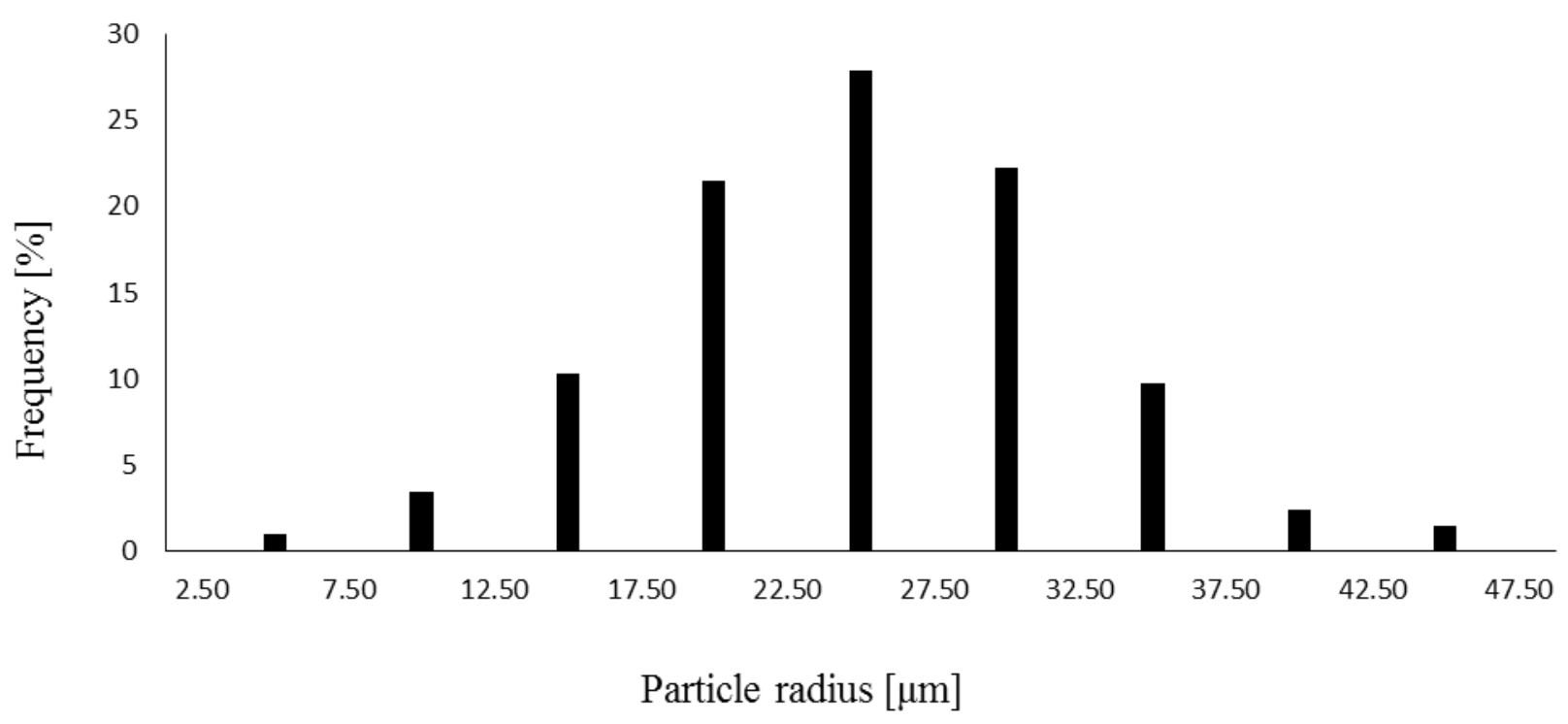

Figure 2-4: Particle size distribution for nominally $50 \mu \mathrm{m}$ particles.

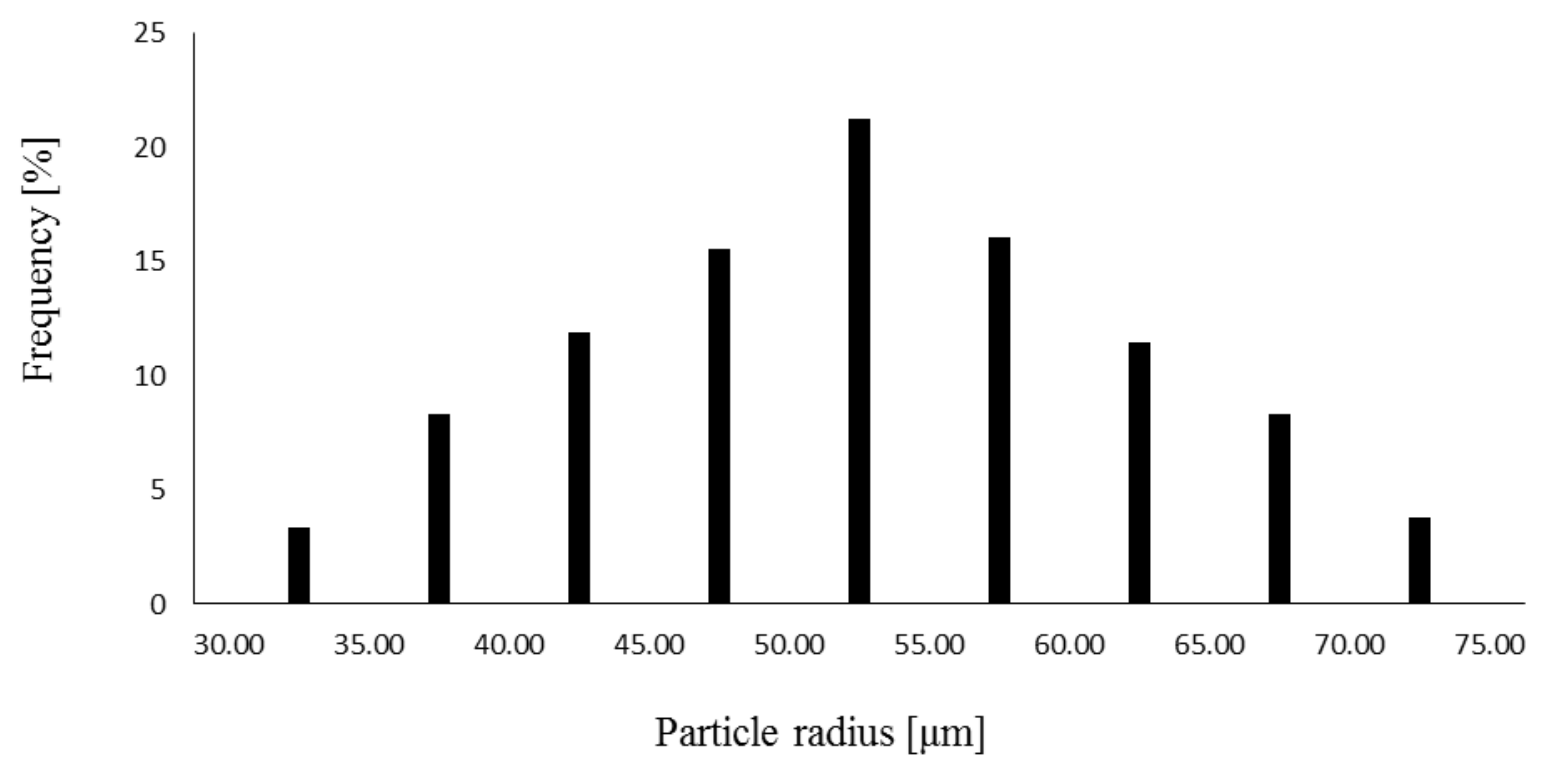

Figure 2-5: Particle size distribution for nominally $100 \mu \mathrm{m}$ particles. 


\subsubsection{Channel measurement}

The differences in blast lag were characterized by measuring the depths of the machined channels entering the intersections $\left(D_{s}\right)$, at the channel intersections $\left(D_{T}, D_{c}\right)$, and on the unmasked portion of the sample $\left(D_{u}\right)$, as indicated in Figure 2-2. All channel depths were measured with an optical profilometer (NANOVEA ST400 Micro Photonics Inc., Irvine, CA, USA, depth resolution of $25 \mathrm{~nm}$; lateral resolution of $0.1 \mu \mathrm{m}$ ). First a full three-dimensional (3D) scan was taken of the whole machined surface. From these, line scans across the channels (i.e., at $90^{\circ}$ to their length) entering the intersections, diagonally (i.e., at $45^{\circ}$ ) across the channel intersections, and on the flat unmasked machined surface were extracted. As an example, Figure 2-6 shows a line scan path taken to obtain the two-dimensional profiles used to determine $D_{c}$ and $D_{s} . D_{u}$ was obtained from a line scan on the unmasked portion of the machined surface. The recorded average depths and associated standard deviations were based on between 6 and 8 such line scans (at different locations along the length of the channels) for three repeat samples at each condition in Table 2-1. Within a given channel, the variation in depth was at most $\pm 1 \mu \mathrm{m}$, so that the reported scatter was mostly due to sample to sample variation.

The absolute depth ratios in the channels leading to the intersection, $k_{s}$, the crossintersection $k_{c}$, and the T-intersection $k_{T}$, were characterized using the ratio of the depth of the machined masked feature to the depth of the machined unmasked target as

Equation 1: $\quad k_{s}=\frac{D_{s}}{D_{u}} \times 100$

Equation 2: $\quad k_{c}=\frac{D_{c}}{D_{u}} \times 100$

Equation 3: $\quad k_{T}=\frac{D_{T}}{D_{u}} \times 100$

With this definition, $k=100 \%$ indicates no blast lag, and lower values of $k$ indicate a higher degree of lag. 
It will be seen that the amount of blast lag within the channels differed from that in the intersections causing the machined channel network in Figure 2-2 and Figure 2-3 to vary in depth. This non-uniformity in depth was quantified using the following ratios

Equation 4: $\quad r_{c}=\frac{D_{s}}{D_{c}} \times 100$

Equation 5:

$$
r_{T}=\frac{D_{S}}{D_{T}} \times 100
$$

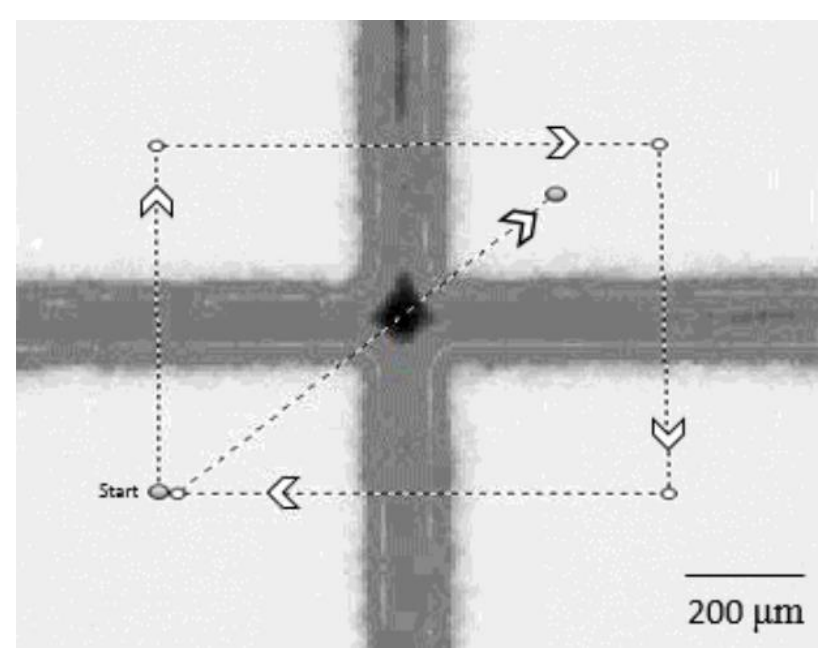

Figure 2-6: Profilometer line scans used to obtain depth of cross-intersection and channels leading to it. $\mathrm{w}=200 \mu \mathrm{m}$ and abrasive particle size was $50 \mu \mathrm{m}$. 


\subsection{Results and Discussion}

It was found that, for all experiments, the mask did not erode sufficiently to affect the mask opening widths, yielding channels that, due to a small amount of undercutting, were slightly wider $(<4.5 \%)$ than the mask opening, but nevertheless all of the same width (maximum difference of $7.7 \mu \mathrm{m}$.

\subsubsection{Absolute depth ratio of masked channels $\left(k_{s}\right)$}

The absolute amount of blast lag within the channels leading to the intersections was characterized by $k_{s}$, the ratio of the channel depths to that of an unmasked area (representing a very wide channel) machined under identical conditions. Figure 2-7, Figure 2-8 and Figure 2-9 show that, for all channel widths $w$, as the particle size decreased, $k_{s}$ increased, indicating a lower blast lag. The figures also show that at any given particle size, increasing $w$ also decreases blast lag. These results are consistent with the results of Wensink and Elwenspoek [6], who suggested that blast lag is reduced using smaller particles or wider channels.

Smaller particles can erode the substrate closer to the mask edges, so the increased channel flux on the sidewalls makes them steeper, thus delaying the onset of the V-shape (Stage II) where blast lag begins. Wider channels also delay the onset of the V-shape, when the two sidewalls meet, resulting in reduced blast lag. Once the $\mathrm{V}$-shape is formed, smaller particles can more easily attack the narrow vertex at the center, also reducing the blast lag. Thus, narrow channel widths and large particles lead to a large amount of blast lag. For example, according to Figure 2-9, using $100 \mu \mathrm{m}$ particles to machine the $100 \mu \mathrm{m}$ width network yields $k_{s}=36 \%$ indicating that the unmasked area is approximately three times deeper than the sides. The relatively large particles are prevented from striking the narrow V-shaped bottom of the channel. 


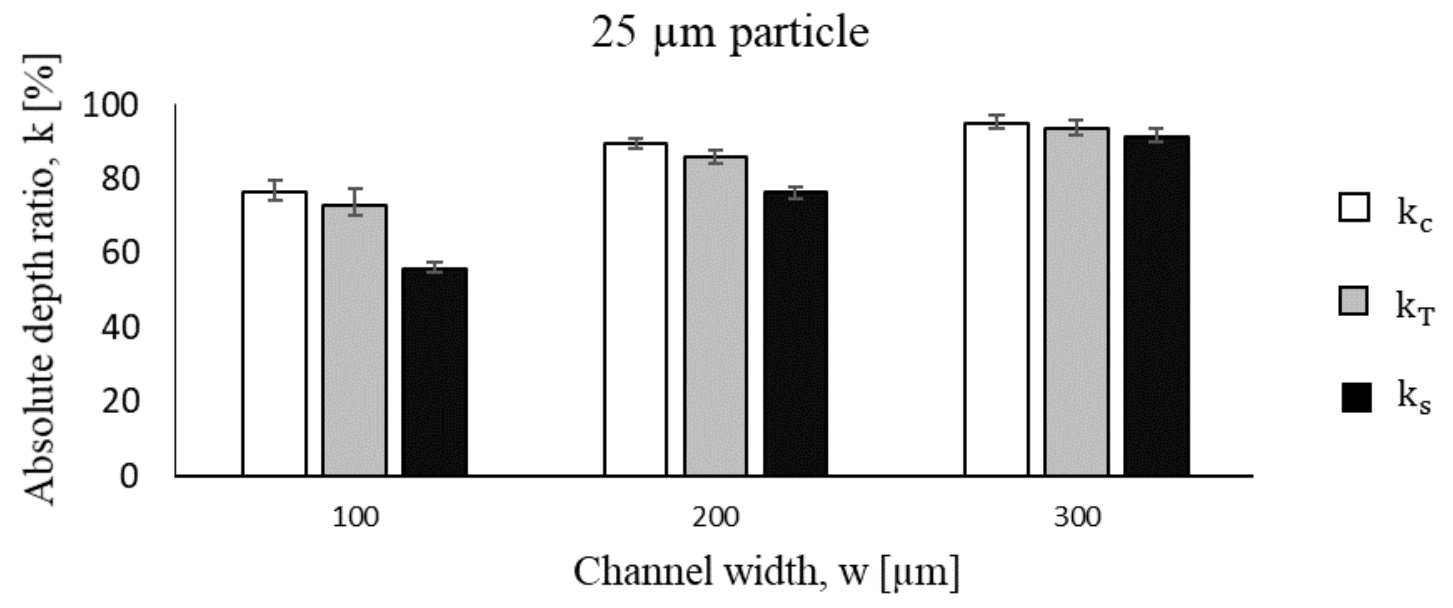

Figure 2-7: Absolute depth ratio of channels and intersections, with respect to unmasked area for $25 \mu \mathrm{m}$ particle size.

$50 \mu \mathrm{m}$ Particle

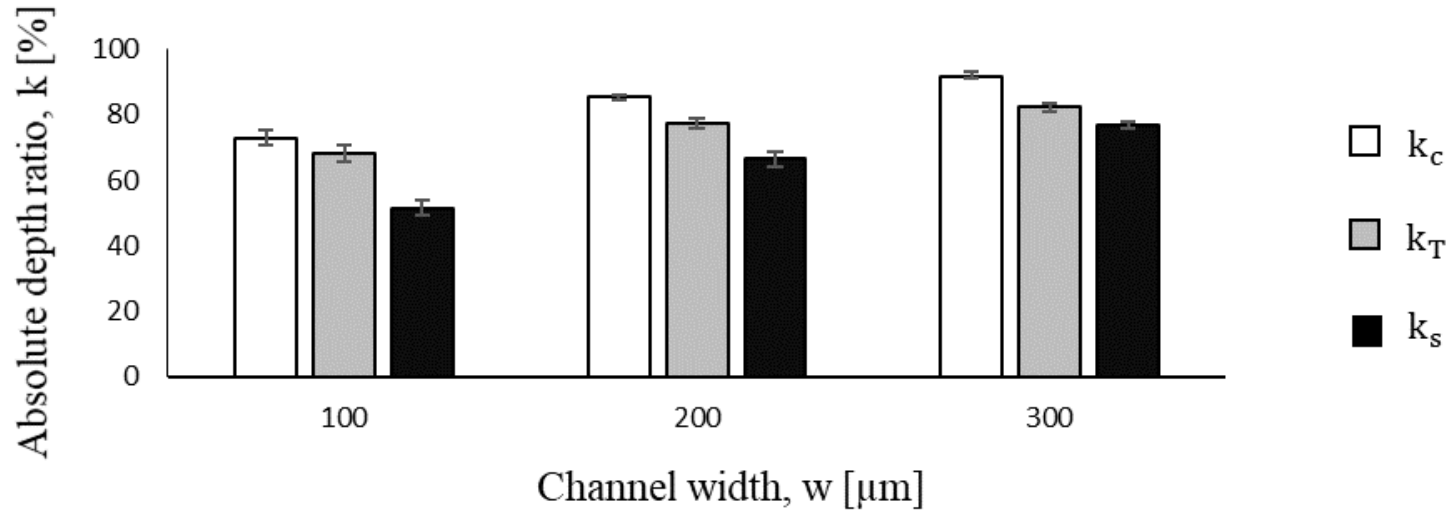

Figure 2-8: Absolute depth ratio of channels and intersections, with respect to unmasked area for $50 \mu \mathrm{m}$ particle size. 


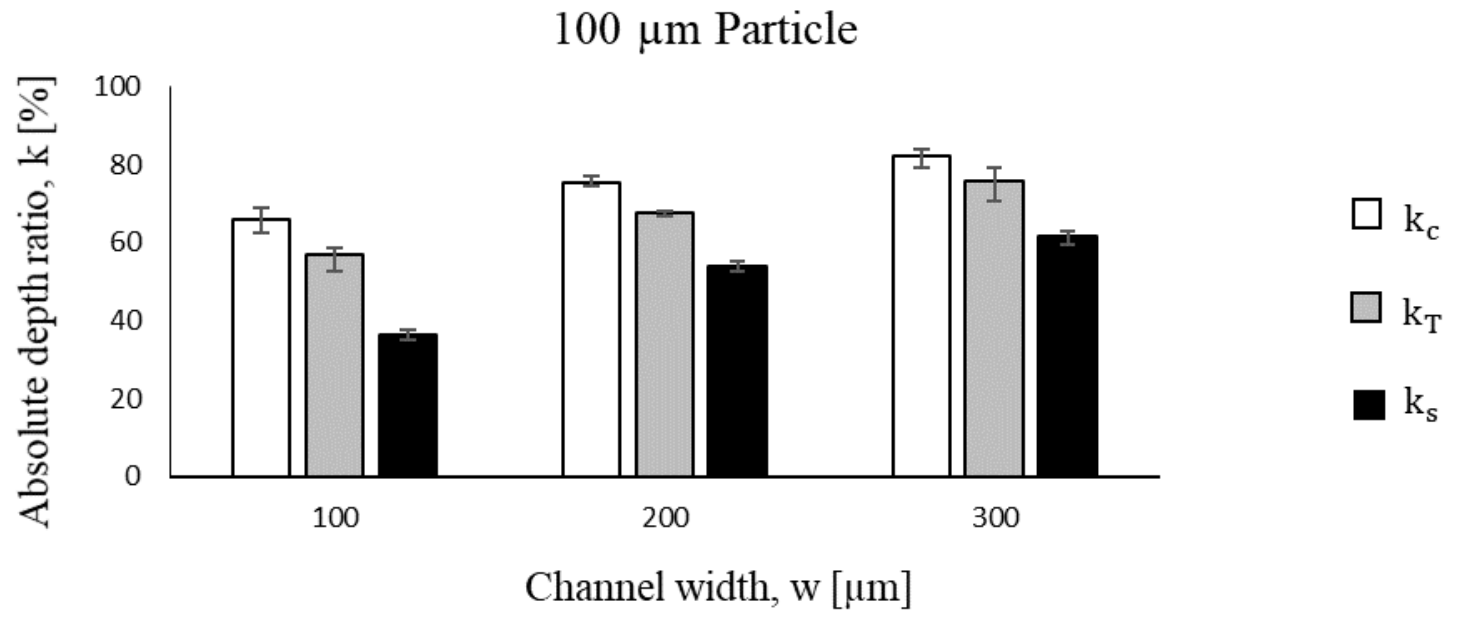

Figure 2-9: Absolute depth ratio of channels and intersections, with respect to unmasked area for $100 \mu \mathrm{m}$ particle size.

\subsubsection{Absolute depth ratio within channel intersection $\left(k_{c}\right.$ and $\left.k_{T}\right)$}

The blast lag within channel intersections has never before been characterized. As seen in Figure 2-7, Figure 2-8 and Figure 2-9, the absolute blast lag at the cross and T-intersections channel show similar trends as were seen for the channels in Section 2.3.1, i.e. decreases in channel width $w$ (implying that the intersections are also narrower) and increases in particle size led to decreases in $k_{c}$ and $k_{T}$ (more blast lag). For example, Figure 2-7 shows that machining the $300 \mu \mathrm{m}$ width network with $25 \mu \mathrm{m}$ particles yielded $k_{c}=95 \%$ and $k_{T}=94 \%$, while much higher blast lags $\left(k_{c}=\right.$ $57 \%$ and $k_{T}=66 \%$ ) were found when machining the $100 \mu \mathrm{m}$ network with $100 \mu \mathrm{m}$ particles (Figure 2-9).

Figure 2-7, Figure 2-8, and Figure 2-9 also show that, in most cases, relatively small, but statistically significant $(\mathrm{p}<0.05)$ differences existed between $k_{c}$ and $k_{T}$, at a given condition. Statistically insignificant differences were seen for the $100 \mu \mathrm{m}$ width eroded using $25 \mu \mathrm{m}$ and 50 $\mu \mathrm{m}$ particles, probably due to the thinner (150 $\mu \mathrm{m}$ compared to 250 and $350 \mu \mathrm{m})$ mask which had slightly more associated scatter because it tended to erode more quickly through its thickness. Thus, in general, the T-intersection exhibited slightly more blast lag (lower $k$ ) than the crossintersection, with the differences becoming more pronounced for larger particles and smaller 
widths. The reason for this small difference is unclear, but it may be related to differences in geometry at the center of the intersections. In other words, the cross-intersection, being open on four sides (corresponding to the four channels leading to it) is more open to particle strikes at its centre, than the T-intersection, which is only open on three sides.

At a given condition, in all cases, $k_{c}$ and $k_{T}$ were significantly larger than $k_{s}$ indicating that the blast lag was lower in the intersections than the channels leading to them. It is hypothesized that the longer diagonal across the intersection effectively makes the intersection act as a wider channel that takes longer to form a $\mathrm{V}$ shape and is thus subjected to less blast lag. The implications of this will be discussed in more detail in Section 2.3.3.

\subsubsection{Comparison and reduction of relative depth ratio $\left(\boldsymbol{r}_{c} \& \boldsymbol{r}_{T}\right)$}

The depth ratios $r_{c}$ and $r_{T}$ (Equation 4 and Equation 5) reflect the difference in the depths

of the cross and T-intersections compared to the channels leading to them, resulting from differences in blast lag at these locations. In other words, if $r_{c}$ or $r_{T}$ do not equal 100, then a 'dimple' will be present at the channel intersections because of the lower blast lag in the intersections compared to the channels (as shown, for example, in Figure 2-10 and Figure 2-11). Such dimples may have undesirable effects on fluid flow in a microfluidic chip. 


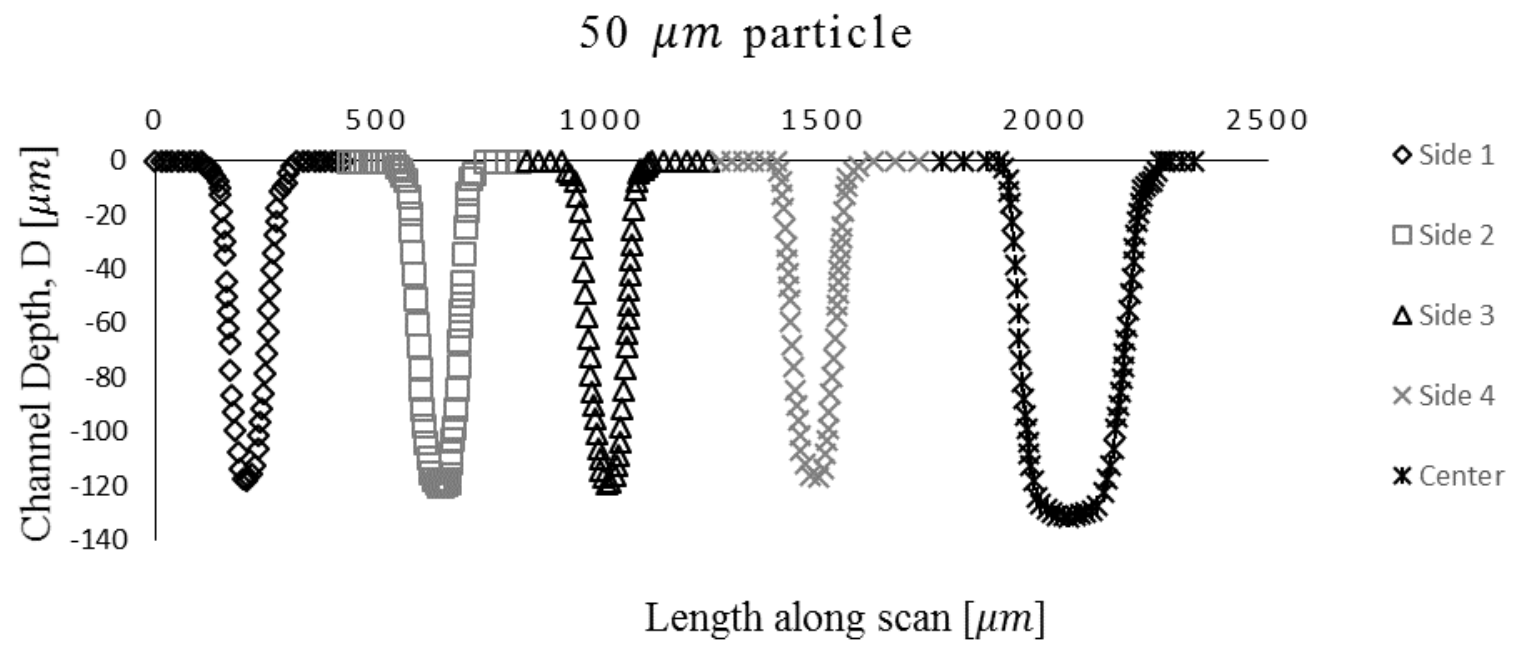

Figure 2-10: Profiles of channels and center of cross-intersection for $50 \mu \mathrm{m}$ particles and $300 \mu \mathrm{m}$ channel width.
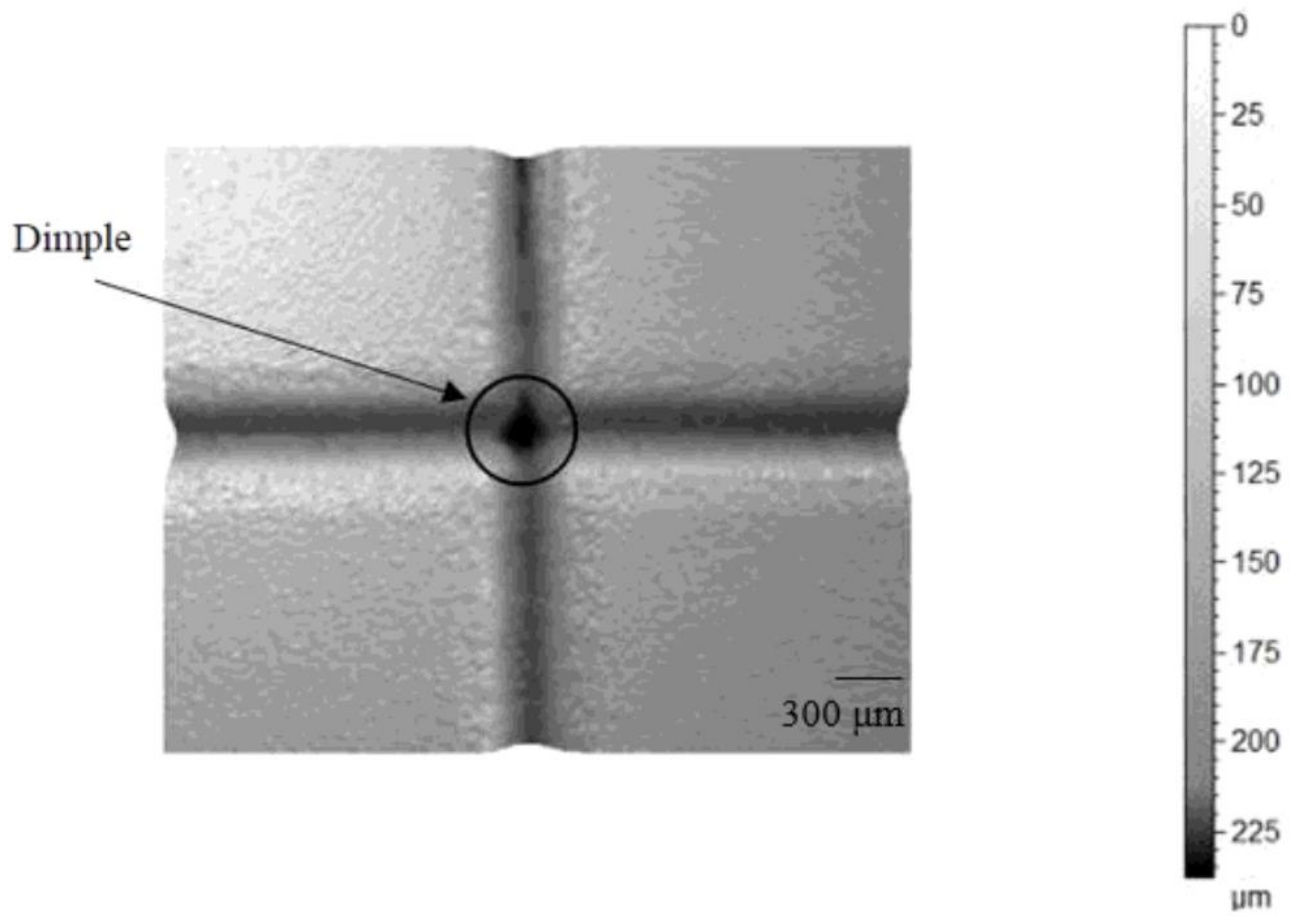

Figure 2-11: 3-D profile channels and cross-intersection for $w=300 \mu \mathrm{m}$ and abrasive particle size of $100 \mu \mathrm{m}$. 
Figure 2-12, Figure 2-13 and Figure 2-14 show that, for a given abrasive particle size, channel networks with larger channel widths result in significantly $(\mathrm{p}<0.05)$ larger values of $r_{c}$ and $r_{T}$. This is expected, because, as seen in Section 2.3.1 and 2.3.2, the absolute blast lag in both the channels and the intersections decreases with channel width. A similar trend and argument can be made for the effect of decreasing particle size. For example, Figure 2-14 indicates that for $100 \mu \mathrm{m}$ channel width and $100 \mu \mathrm{m}$ particles, $r_{c}=\frac{D_{s}}{D_{c}}=55 \%$ meaning that the depth of the crossintersection is approximately double the depth of the channels leading to it. On the other hand, according to Figure $2-12, r_{c}=\frac{D_{s}}{D_{c}}=95 \%$ for $300 \mu \mathrm{m}$ width and $25 \mu \mathrm{m}$ particles indicating very little difference in depth between the channels and center of the cross-intersection.

\section{$25 \mu \mathrm{m}$ Particle}

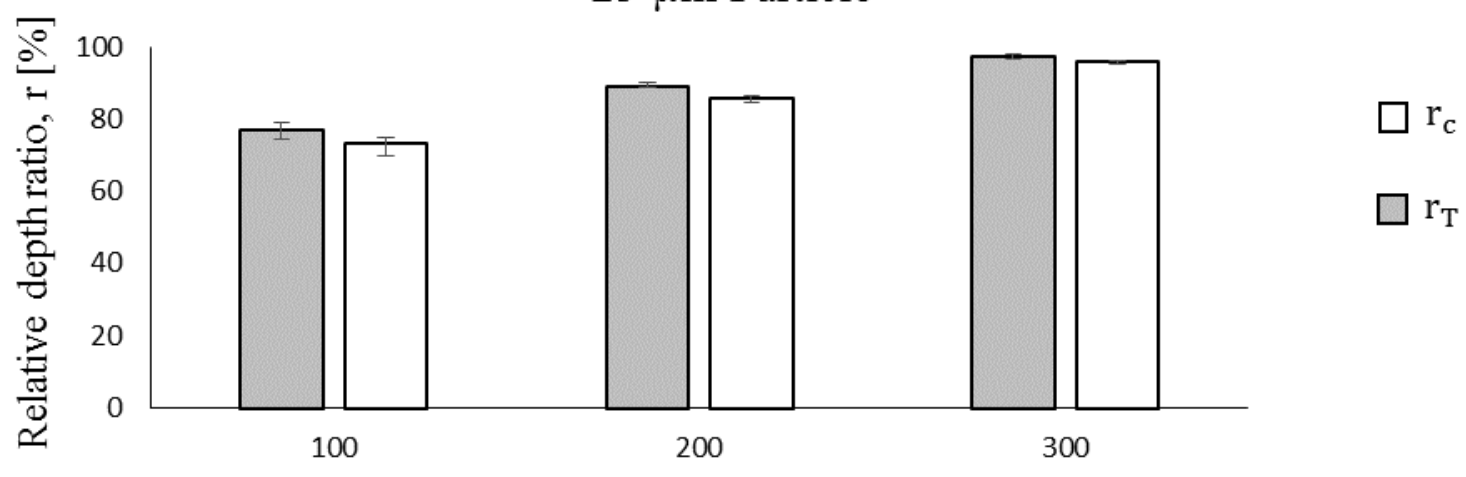

Channel width, w [ $\mu \mathrm{m}]$

Figure 2-12: Relative depth ratio between channels and intersections for $25 \mu \mathrm{m}$ particles. 
$50 \mu \mathrm{m}$ Particle

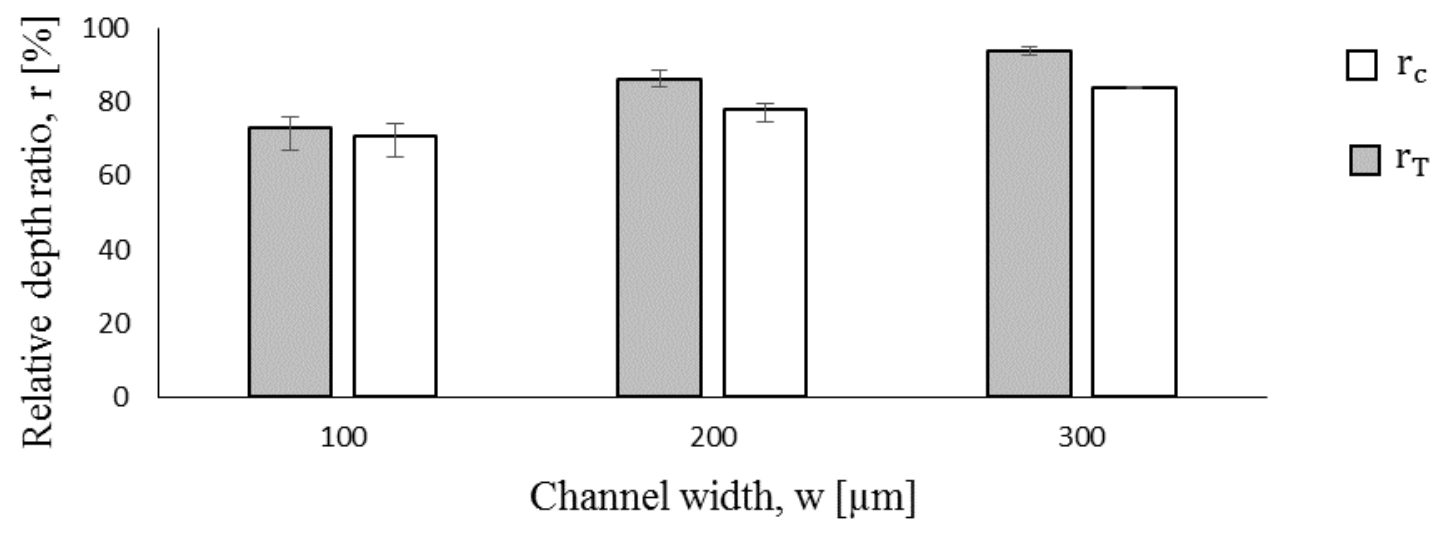

Figure 2-13: Relative depth ratio between channels and intersections for $50 \mu \mathrm{m}$ particles.

$100 \mu \mathrm{m}$ Particle

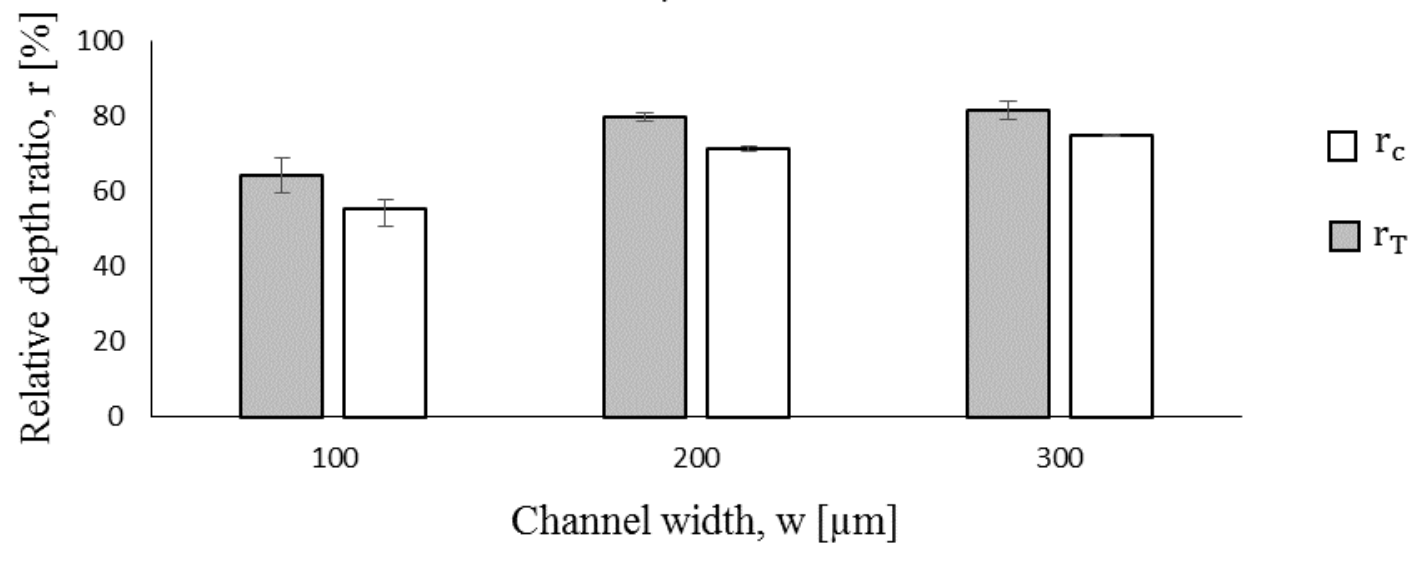

Figure 2-14: Relative depth ratio between channels and intersections for $100 \mu \mathrm{m}$ particles. 


\subsubsection{Reduction of differences in blast lag in microfluidic networks}

As seen in Figure 2-15 and Figure 2-16, for very wide channels (e.g. $550 \mu \mathrm{m}$ ) the differences in blast lag can be reduced so that the dimple at the channel intersection disappears. Furthermore, for ductile targets, U-shaped channels and intersections will form, in which case there will be no blast lag. For narrower channels in brittle materials, however, the only viable option is to decrease the particle size. As seen in the previous sections, decreasing the particle size will result in a reduction of absolute blast lag in both the channels (Section 2.3.1) and the intersections (Section 2.3.2). Indeed, comparing Figure 2-17 with Figure 2-7, Figure 2-8 and Figure 2-9 shows that the amount of absolute blast lag for the channels $\left(k_{S}\right)$, cross-intersection $\left(k_{c}\right)$ and T-intersection $\left(k_{T}\right)$ greatly decreases when using $10 \mu \mathrm{m}$ particles compared to $25-100 \mu \mathrm{m}$. For the $300 \mu \mathrm{m}$ width, the absolute blast lags are virtually absent, and Figure 2-18 shows that the depths of the channels and intersections are almost equal, i.e. are $r_{c}=\frac{D_{S}}{D_{c}}=95 \%$ and $r_{T}=\frac{D_{S}}{D_{T}}=96 \%$. As can be seen in Figure 2-19, the dimple at the intersection is eliminated.

The disadvantages of reducing particle size is that the target removal rate would decrease. However, this could be counteracted by increasing the particle speed, so that the removal rate would be partially restored [6]. 
$50 \mu m$ particle

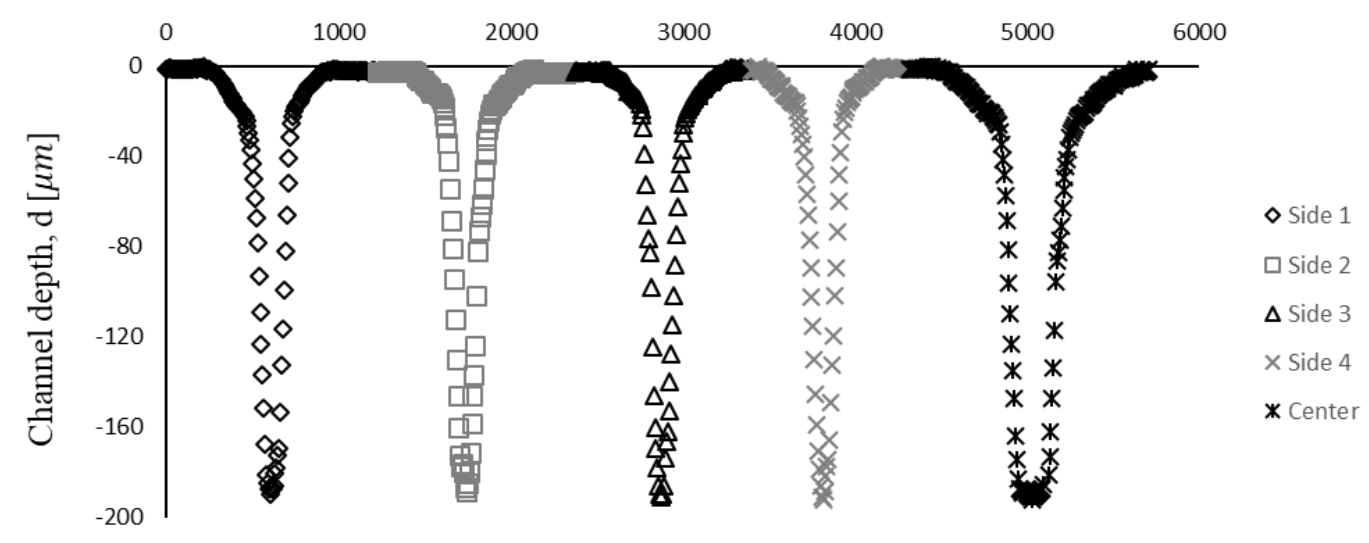

Length along scan $[\mu m]$

Figure 2-15: Profiles of channels and center of cross-intersection for $50 \mu \mathrm{m}$ particle and $550 \mu \mathrm{m}$ channel width.
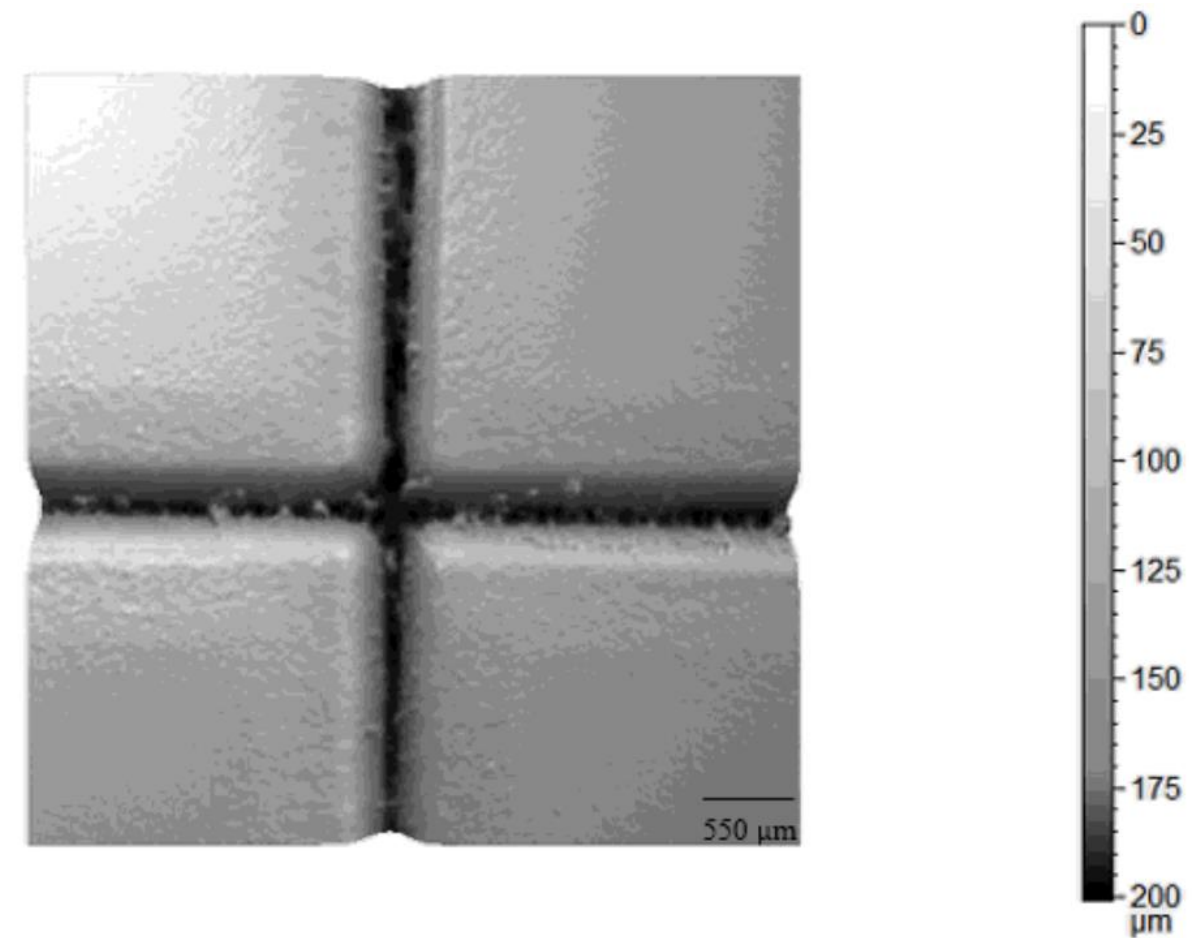

Figure 2-16: 3-D profiles for $550 \mu \mathrm{m}$ channel width and $50 \mu \mathrm{m}$ particle. 


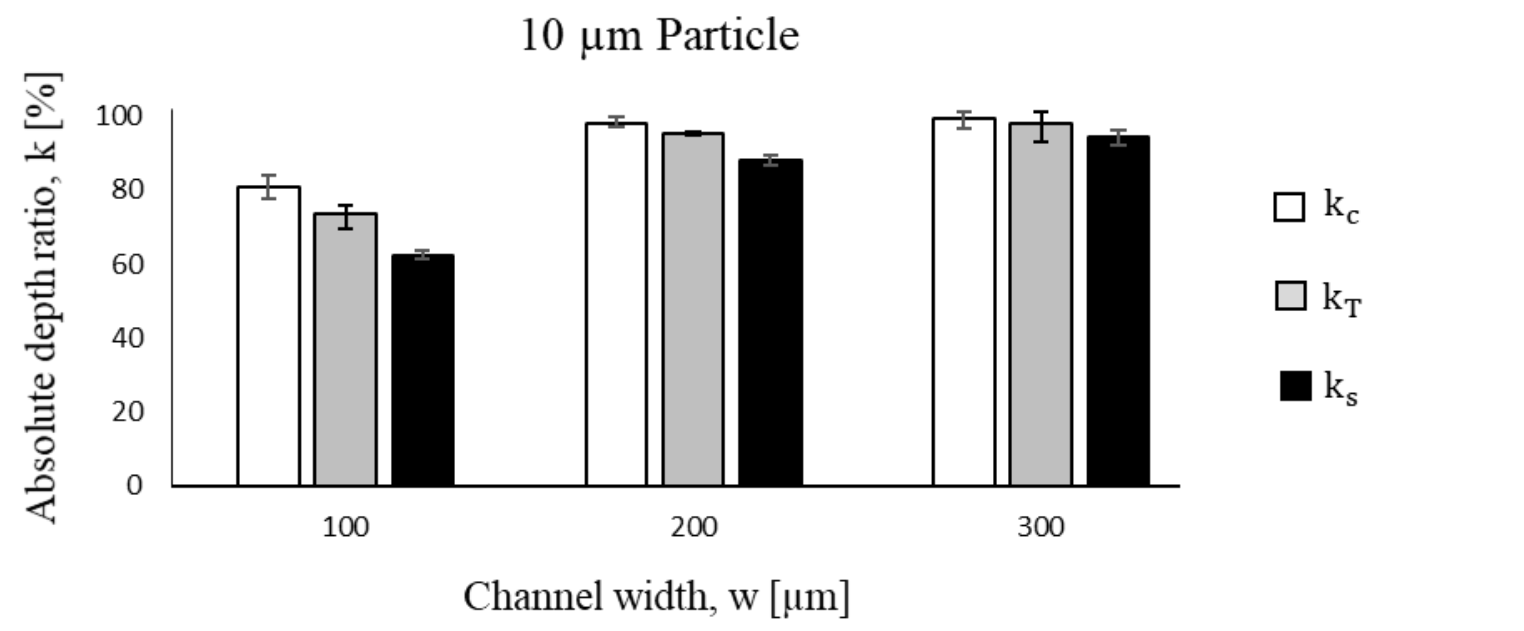

Figure 2-17: Absolute depth ratio of channels and intersections, with respect to unmasked area for $10 \mu \mathrm{m}$ particle size.

$10 \mu \mathrm{m}$ Particle

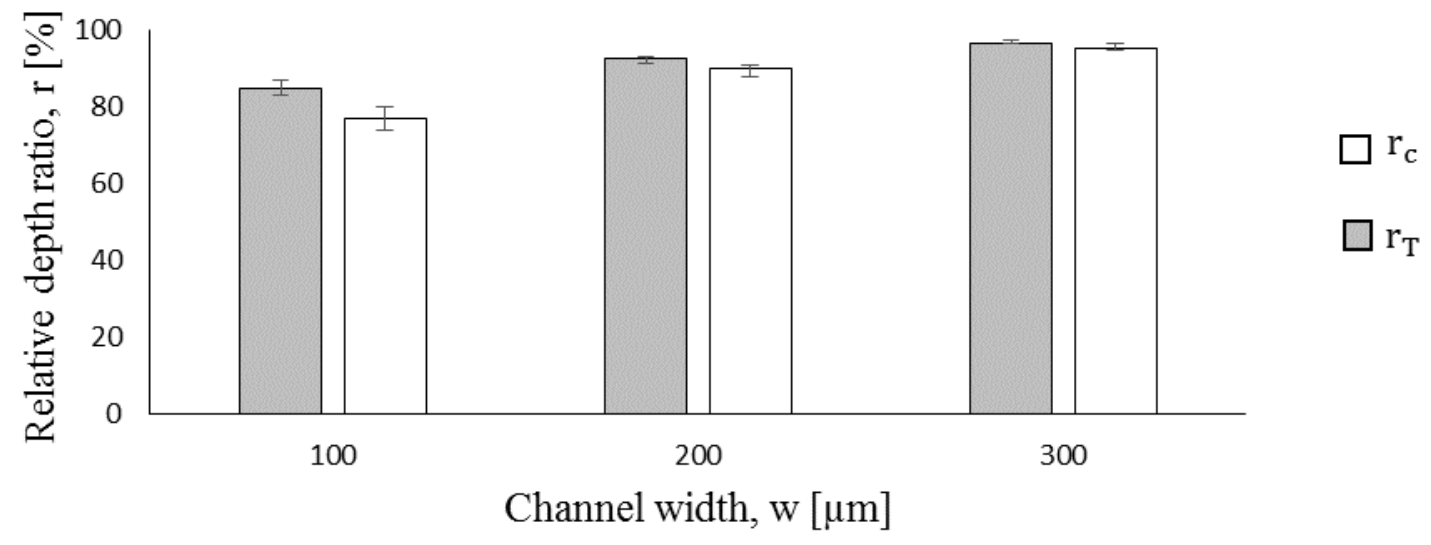

Figure 2-18: Relative depth ratio between channels and intersections for $10 \mu \mathrm{m}$ particles. 


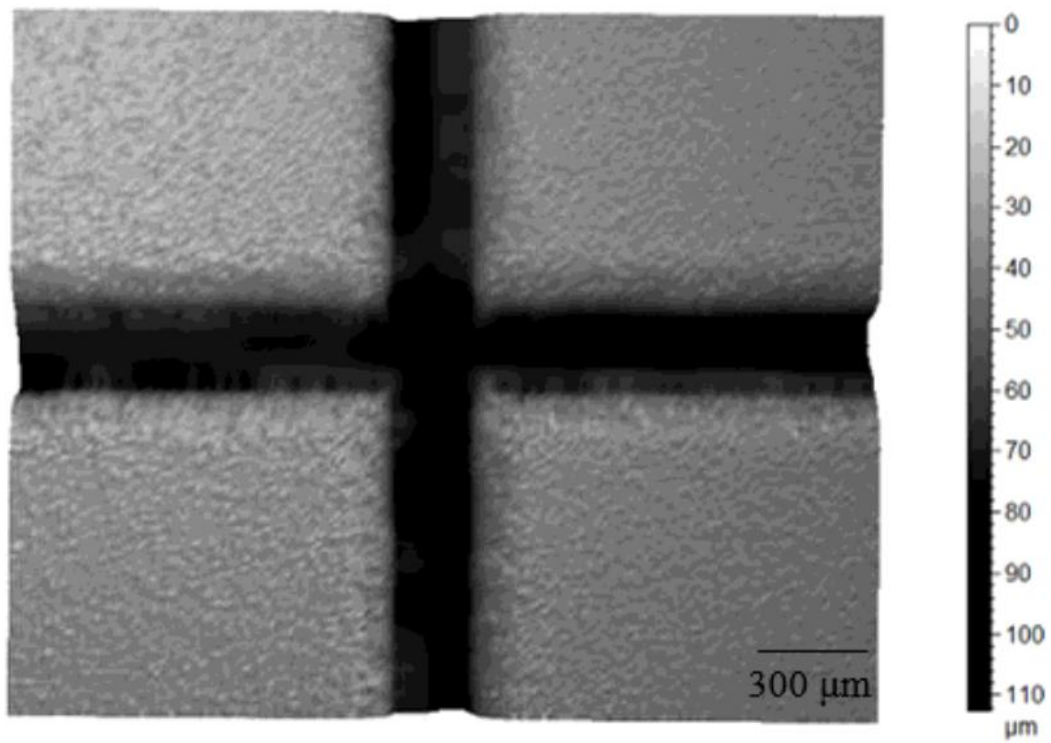

Figure 2-19: 3-D profile of cross-intersection for a channel width of $300 \mu \mathrm{m}$ and abrasive particle size of $10 \mu \mathrm{m}$.

\subsubsection{Model}

Surface evolution models have been used in the past to predict the evolving shape of channel profiles as they are subject to an increasing number of nozzle passes [7]. Details can be found in Ref. [7] and the Appendix of this thesis, but briefly, such models take as input a distribution of 'erosive efficacy' corresponding to the spatial and velocity distribution of particle strikes on the surface, and output the profile at any time (or number of passes). The erosive efficacy distribution can be determined easily from a measurement of a shallow profile resulting from a rapid pass of the nozzle over the target. The models take into account the time-varying spread in local particle strike angles across the eroding channel as the sidewalls become steeper. In the case of brittle targets, considering only the damage due to the component of incident velocity perpendicular to the surface has been found to give accurate predictions of eroding topography. 
What results is a partial differential equation that can be solved for the time evolving shape of the eroding feature $[7,17,25]$.

Since blast lag in channels is known to be affected by the shape of the profile (i.e., larger particles are hindered from reaching the center as the profile become V-shaped) [6], the possibility of using a surface evolution model to predict the onset of blast lag was explored. Therefore, the surface evolution model of Ghobeity et al. [7] for brittle materials was used to determine the depth of the channel and intersections when the onset of blast lag occurs, i.e., the number of passes necessary for the feature to become V-shaped and sufficiently narrow at its bottom for the largest particle in the particle distribution to begin to interfere with the sidewalls of the evolving machined feature along its centerline. As an approximation, the development of the 3D intersection topography was assumed to behave as a 2D profile across its diagonal. To do this, first the erosive efficacies incident to the channels and the section diagonally across of the cross-intersection were extracted from measured shallow profiles using a single nozzle pass and used as the input to the surface evolution model. Details regarding the numerical solution of the partial differential equation can be found in [7]. The bottom of predicted profile after each pass was compared to the largest recordable particle, i.e. representing the size above which only $<5 \%$ of the particles exist, in the size distribution to determine whether it would interfere with the sidewalls. For simplicity the particle was assumed spherical, consistent with the equivalent spherical diameter that was used to represent the size distribution (Table 2-1).

In this manner, the surface evolution model was used to determine the number of passes required to propagate the surfaces (channel and intersections) such that their centerlines could no longer be struck by the largest particle, i.e. the onset of blast lag in each of the channel and 
intersection. To demonstrate how such a model can be used, trials were conducted for a constant $200 \mu \mathrm{m}$ channel width network, but with different abrasive particle sizes.

As shown in Figure 2-20 for $100 \mu \mathrm{m}$ particles, at 4 passes the largest particles in the distribution (radius, $r=72.5 \mu \mathrm{m}$ ) start to interfere with the sidewalls at the channel centerline. At this point, blast lag begins since these larger particles can no longer strike the centerline of the channels. At approximately 7.4 passes, the largest particle size $(r=72.5 \mu \mathrm{m})$ begins to interfere with the sidewall of the cross-intersection. The difference in depths corresponding to the onset of blast lag for the channels and intersection is the maximum possible difference in blast lag. It is considered the maximum blast lag difference because of the continued erosion at a lower flux after the predicted onset of blast lag. In other words, since 10 passes in total were used to erode the networks, in reality, the channels and intersection were subjected to a further 6 and 2.6 passes, respectively, at a reduced flux (i.e., with the smaller particles that could still erode the channel centre) after the onset of blast lag. Thus, the actual depth difference will be smaller than that predicted by this model. The predicted onset of blast lag is shown in Figure 2-20, Figure 2-21 and Figure 2-22, for three particle sizes and a $200 \mu \mathrm{m}$ wide channel network. The predicted depth ratios at the onset of blast lag are compared to the measured actual depth ratios (Figure 2-13, Figure 2-14 and Figure 2-18) in Table 2-3.

As expected, the predicted $r_{c}$ values are, in most cases, significantly lower (higher blast lag difference) than the measured. However, the trends are consistent with the experiments, i.e. the larger the particle, the greater is the blast lag difference between channel and intersection (lower $r_{c}$ ). The model also correctly demonstrates that the intersection, being effectively wider (across a diagonal) than the channel leading to it, develops a V-shape (and thus begins to exhibit blast lag) later (more passes) than the channels. The model also correctly predicts that differences in blast 
lag will be negligible for the $10 \mu \mathrm{m}$ particle size. Finally, it correctly predicts that the depth ratios will be relatively close for the 50 and $100 \mu \mathrm{m}$ particles.

In summary, although the model can only predict the maximum possible difference in blast lag (minimum $r_{c}$ ), it nevertheless can be a valuable design tool to determine when differences in blast lag between channels and intersections can be expected.

Table 2-3: Predictions of surface evolution model

\begin{tabular}{|l|c|c|c|}
\hline Nominal Particle size $(\mu \mathrm{m})$ & 10 & 50 & 100 \\
\hline Width of the mask $(\mu \mathrm{m})$ & 7.5 & 37.5 & 72.5 \\
\hline Maximum particle radius size used in model. $(\mu \mathrm{m})$ & 10 & 6.2 & 4 \\
\hline $\begin{array}{l}\text { Predicted number of passes required for largest } \\
\text { particle to interfere with the sidewalls of channels }\end{array}$ & 10 & 8.4 & 7.4 \\
\hline $\begin{array}{l}\text { Predicted number of passes required for largest } \\
\text { particle to interfere with the sidewalls of cross- } \\
\text { intersection. }\end{array}$ & $100 \%$ & $57 \%$ & $52 \%$ \\
\hline $\begin{array}{l}\text { Maximum depth ratio (relative blast lag) predicted by } \\
\text { model }\left(r_{c} \%\right)\end{array}$ & $92 \%$ & $76 \%$ & $70 \%$ \\
\hline $\begin{array}{l}\text { Measured depth ratio (relative blast lag) in } \\
\text { experiments }\left(r_{c} \%\right)\end{array}$ & & & \\
\hline
\end{tabular}




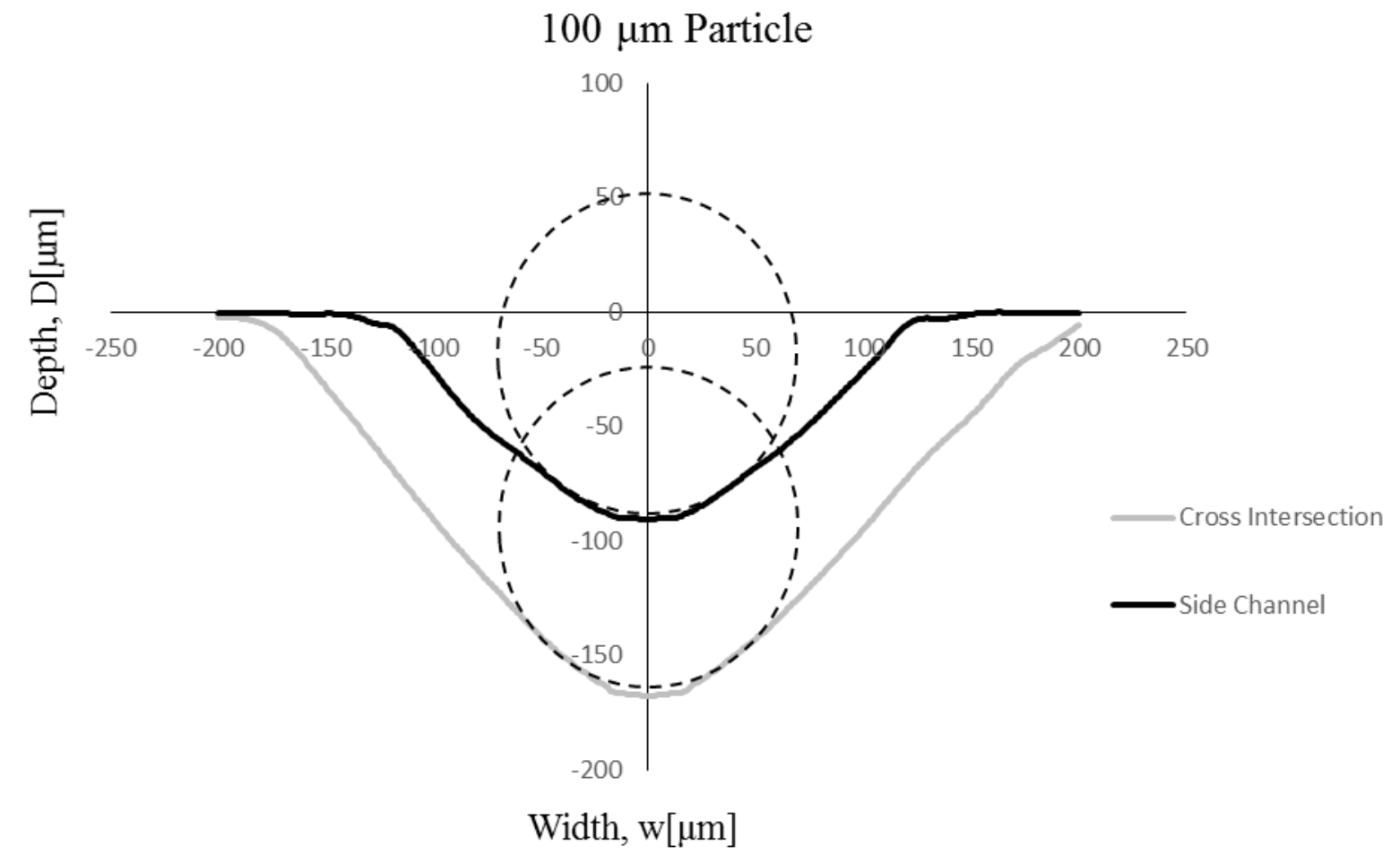

Figure 2-20: Predictions of surface evolution model for $200 \mu \mathrm{m}$ wide channel network and 100 $\mu \mathrm{m}$ nominal particle size. The dashed circles represent the largest particle in the distribution (145 $\mu \mathrm{m})$ at the point where blast lag begins in the channels and intersection. The difference in depths shows the maximum difference in blast lag. 


\section{$50 \mu \mathrm{m}$ Particle}

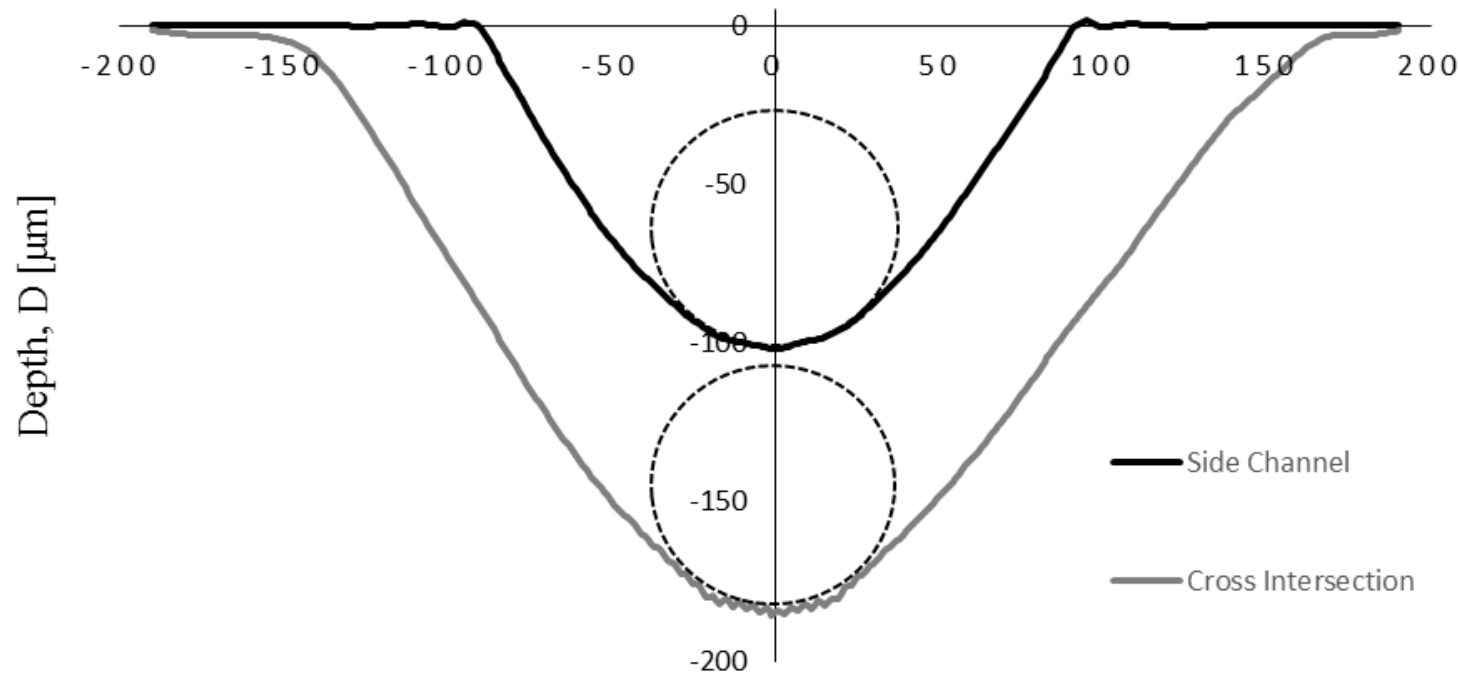

Width, $\mathrm{w}[\mu \mathrm{m}]$

Figure 2-21: Predictions of surface evolution model for $200 \mu \mathrm{m}$ wide channel network and $50 \mu \mathrm{m}$ nominal particle size. The dashed circles represent the largest particle in the distribution $(75 \mu \mathrm{m})$ at the point where blast lag begins. The difference in depths shows the maximum difference in blast lag. 


\section{$10 \mu \mathrm{m}$ Particle}

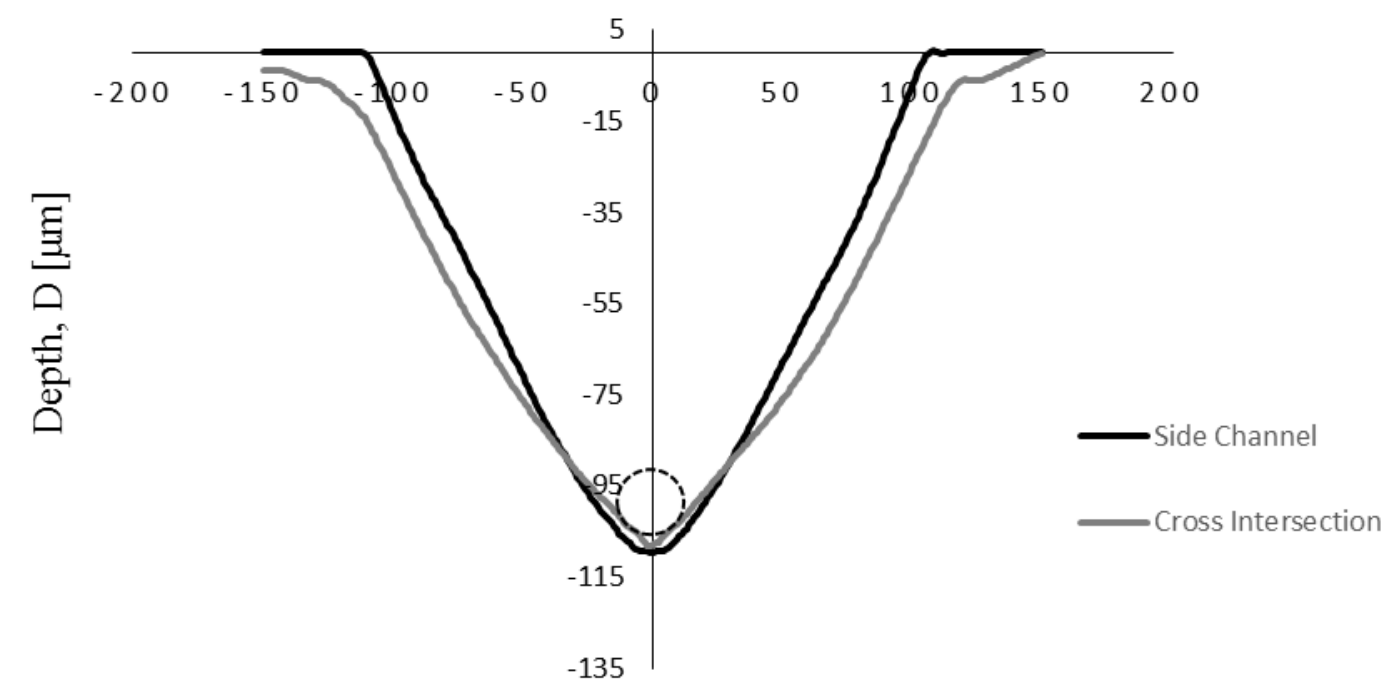

Width, $w[\mu \mathrm{m}]$

Figure 2-22: Predictions of surface evolution model for $200 \mu \mathrm{m}$ wide channel network and $10 \mu \mathrm{m}$ nominal particle size. The dashed circles represent the largest particle in the distribution $(15 \mu \mathrm{m})$ at the point where blast lag begins. The difference in depths shows the maximum difference in blast lag. 


\section{Conclusions and Future Work}

\subsection{Conclusions}

The major conclusions of the thesis can be summarized as follows:

i. For the first time, differences in relative blast lag between channel intersections and the channels themselves in a microfluidic network machined using AJM have been reported. These differences because recessed dimples to form in the intersections, which may be of concern for microfluidic applications. The dimple is worst when a chip with narrow channels is made using large abrasive particles. The best way to avoid the dimple for a given channel width is by reducing the particle size, at the penalty of a lower material removal rate.

ii. The absolute blast lag decreased in both the channels and intersections when the channel width was increased and the particle size decreased, because these conditions allow abrasive particles to strike the feature centerline. In the case of wider channels, the transition from a U-shaped to $\mathrm{V}$-shaped is delayed.

iii. Absolute blast lag was slightly greater in T-intersections than cross-intersections due to the difference in geometric constraint (3 openings in T-intersection compared to 4 in crossintersections).

iv. For the first time, a surface evolution model was used to predict the onset of blast lag i.e., when a particle of largest size in a particle distribution begins to interfere with the sidewalls of an evolving machined feature along its centerline, for both channels and intersections. The behavior of the 3D intersection was demonstrated to be adequately represented by a 2D profile across its diagonal. The model can be a valuable tool to allow prediction of the number passes after which the relative blast lag between the channel and intersection becomes significant, and dimples form in channel networks. 


\subsection{Recommendations for future work}

The research presented in this thesis could be extended to study the following other interesting aspects of blast lag in AJM and microfluidic chip fabrication.

i. Determine the relative and absolute blast lags for different angles of intersecting channels and compare them with perpendicular cross-intersection and T-intersections.

ii. Develop a method to reduce the blast lag in microfluidic chip other than reducing particle size or increasing the width of the channel. The use of inclined nozzles (oblique blasting) may be a first step. In addition, changing the geometry of the cross-intersection on the metal mask (e.g. changing the angle of the intersecting channels) might be an effective way to reduce the blast lag.

iii. Refine the existing two-dimensional surface evolution model to allow prediction of evolving channel cross sections after blast lag has begun thus improving the predictions of the models presented in this thesis.

iv. Develop a 3D surface evolution equation that allows prediction of the evolving 3D geometry of the channel intersections. It could then be used to rigorously explain the differences between blast lag in $\mathrm{T}$ and cross- intersections. 


\section{Appendix A - Surface evolution equation}

The surface evolution equation for AJM of a brittle material is [7]

$z_{t}=E(x)\left(1+\left(z_{x}\right)^{2}\right)^{-\beta / 2}$

Where $E(x)=\emptyset(x) V(x)^{\beta}$ is the erosive efficacy.

In equation A.1, $z_{t}$ is the partial derivative of the profile depth $z$ with respect to time, $t$ (or number of passes), $z_{x}$ is the slope of the profile, and $\beta$ is the velocity constant. $\emptyset(x)$ and $V(x)$ are the abrasive particle mass flux and velocity distributions respectively incident to the target between the edges of the mask.

This partial differential equation can be solved to determine the eroded profile after any number of passes (represented by time, $t$ ) if $E(x)$, the erosive efficacy, is known. $E(x)$ can be determined from a shallow first pass profile of the eroded surface. To solve eq. (A.1), the pdesolve function was used in MathCad 13 with 200 time steps and 200 space steps. The initial condition was $z(x, 0)=0$ (initially flat surface), and the boundary conditions were $z(w / 2, t)=$ $z(-w / 2, t)=0$ (indicating the constraints of the mask edges on the profile at $x=w / 2$ and $x=$ $-w / 2$.

In this manner, using the measured first pass profile to obtain $\mathrm{E}(\mathrm{x})$, eq. (A.1) was solved and the eroded profiles after 1 to 10 passes were determined for the cases described in Section 2.3.5. 


\section{References}

[1] Slikkerveer PJ, Veld FHIT. Model for patterned erosion. Wear 1999;233-235:377-86. doi:10.1016/S0043-1648(99)00177-5.

[2] V K Jain. Micro Machining Processes. SAGE Publications Sage UK: London, England; 2014.

[3] Solignac D, Sayah A, Constantin S, Freitag R, Gijs MAM. Powder blasting for the realisation of microchips for bio-analytic applications. Sensors Actuators, A Phys 2001;92:388-93. doi:10.1016/S0924-4247(01)00577-5.

[4] Ahmadzadeh F, Tsai SSH, Papini M. Effect of curing parameters and configuration on the efficacy of ultraviolet light curing self-adhesive masks used for abrasive jet micromachining. Precis Eng 2017;49:354-64.

[5] Getu H, Ghobeity A, Spelt JK, Papini M. Abrasive jet micromachining of polymethylmethacrylate. Wear 2007;263:1008-15.

[6] Wensink H, Elwenspoek MC. Reduction of sidewall inclination and blast lag of powder blasted channels. Sensors Actuators A Phys 2002;102:157-64.

[7] Ghobeity A, Krajac T, Burzynski T, Papini M, Spelt JK. Surface evolution models in abrasive jet micromachining. Wear 2008;264:185-98.

[8] Hadavi V, Michaelsen B, Papini M. Measurements and modeling of instantaneous particle orientation within abrasive air jets and implications for particle embedding. Wear 2015;336:9-20.

[9] Ciampini D, Spelt JK, Papini M. Simulation of interference effects in particle streams following impact with a flat surface: Part I. Theory and analysis. Wear 2003;254:237-49.

[10] Ghobeity A, Crabtree HJ, Papini M, Spelt JK. Characterisation and comparison of microfluidic chips formed using abrasive jet micromachining and wet etching. J Micromechanics Microengineering 2012;22:25014.

[11] Burzynski T, Papini M. Level set methods for the modelling of surface evolution in the abrasive jet micromachining of features used in MEMS and microfluidic devices. J Micromechanics Microengineering 2010;20:1-17. doi:10.1088/0960-1317/20/8/085004.

[12] Slikkerveer PJ, Bouten PCP, De Haas FCM. High quality mechanical etching of brittle 
materials by powder blasting. Sensors Actuators A Phys 2000;85:296-303.

[13] Wensink H, Berenschot JW, Jansen H V, Elwenspoek MC. High resolution powder blast micromachining. Proc. IEEE Thirteen. Annu. Int. Conf. Micro Electro Mech. Syst. (Cat. No. 00CH36308), IEEE; 2000, p. 769-74.

[14] Pu Q, Luttge R, Gardeniers HJGE, van den Berg A. Comparison of capillary zone electrophoresis performance of powder-blasted and hydrogen fluoride-etched microchannels in glass. Electrophoresis 2003;24:162-71.

[15] Jafar RHM, Spelt JK, Papini M. Numerical simulation of surface roughness and erosion rate of abrasive jet micro-machined channels. Wear 2013;303:302-12.

[16] Burzynski T, Papini M. A level set methodology for predicting the surface evolution of inclined masked micro-channels resulting from abrasive jet micro-machining at oblique incidence. Int J Mach Tools Manuf 2011;51:628-41.

[17] Ally S, Spelt JK, Papini M. Prediction of machined surface evolution in the abrasive jet micro-machining of metals. Wear 2012;292:89-99.

[18] Jafar RHM, Spelt JK, Papini M. Surface roughness and erosion rate of abrasive jet micromachined channels: Experiments and analytical model. Wear 2013;303:138-45.

[19] Saragih AS, Ko TJ. Fabrication of passive glass micromixer with third-dimensional feature by employing SU8 mask on micro-abrasive jet machining. Int J Adv Manuf Technol 2009;42:474-81.

[20] Ghobeity A, Getu H, Papini M, Spelt JK. Surface evolution models for abrasive jet micromachining of holes in glass and polymethylmethacrylate (PMMA). J Micromechanics Microengineering 2007;17:2175.

[21] Li H, Lee A, Fan J, Yeoh GH, Wang J. On DEM-CFD study of the dynamic characteristics of high speed micro-abrasive air jet. Powder Technol 2014;267:161-79.

[22] Dehnadfar D, Friedman J, Papini M. Laser shadowgraphy measurements of abrasive particle spatial, size and velocity distributions through micro-masks used in abrasive jet micro-machining. J Mater Process Technol 2012;212:137-49.

[23] Ghobeity A, Papini M, Spelt JK. Abrasive jet micro-machining of planar areas and transitional slopes in glass using target oscillation. J Mater Process Technol 2009;209:5123-32. doi:10.1016/j.jmatprotec.2009.02.012. 
[24] Ghobeity A, Ciampini D, Papini M. An analytical model of the effect of particle size distribution on the surface profile evolution in abrasive jet micromachining. J Mater Process Technol 2009;209:6067-77.

[25] Burzynski T, Papini M. Modelling of surface evolution in abrasive jet micro-machining including particle second strikes: A level set methodology. J Mater Process Technol 2012;212:1177-90. 